\title{
Article \\ Effect of Yuzu (Citrus junos) Seed Limonoids and Spermine on Intestinal Microbiota and Hypothalamic Tissue in the Sandhoff Disease Mouse Model
}

\author{
Mayumi Minamisawa ${ }^{1,2, *}$, , Takuma Suzumura ${ }^{2}$, Sudeep Bose ${ }^{3}$, Tetsuyuki Taniai ${ }^{1}$, Gota Kawai ${ }^{1,2}{ }^{(D}$, \\ Kyoko Suzuki ${ }^{4}$, Akira Yamaguchi ${ }^{5}$ and Shoji Yamanaka ${ }^{5}$ \\ 1 Faculty of Advanced Engineering, Chiba Institute of Technology, 2-1-1 Shibazono Narashino, \\ Chiba 275-0023, Japan; drtaniai@mx3.ttcn.ne.jp (T.T.); gota.kawai@p.chibakoudai.jp (G.K.) \\ 2 Graduate School of Engineering, Chiba Institute of Technology, 2-17-1 Tsudanuma Narashino, \\ Chiba 275-0016, Japan; ibcb.takusuzu@gmail.com \\ 3 Amity Institute of Biotechnology and Molecular Medicine, Amity University, Uttar Pradesh, \\ Noida 201313, India; sbose1@amity.edu \\ 4 School of Medicine, Yokohama City University, 3-9 Fukuura Kanazawa Kanagawa, \\ Yokohama 236-0004, Japan; ksuzuki@yokohama-cu.ac.jp \\ 5 Department of Pathology, Yokohama City University, Yokohama 236-0004, Japan; \\ yamaguchiakira@me.com (A.Y.); kowanyamanaka@gmail.com (S.Y.) \\ * Correspondence: minamisawa.mayumi@p.chibakoudai.jp; Tel.: +81-43-377-3759
}

check for

updates

Citation: Minamisawa, M.; Suzumura, T.; Bose, S.; Taniai, T.;

Kawai, G.; Suzuki, K.; Yamaguchi, A.; Yamanaka, S. Effect of Yuzu (Citrus junos) Seed Limonoids and Spermine on Intestinal Microbiota and Hypothalamic Tissue in the Sandhoff Disease Mouse Model. Med. Sci. 2021, 9, 17. https://doi.org/10.3390/ medsci9010017

Academic Editor: Noriyuki Murai

Received: 25 December 2020

Accepted: 8 March 2021

Published: 11 March 2021

Publisher's Note: MDPI stays neutral with regard to jurisdictional claims in published maps and institutional affiliations.

Copyright: (c) 2021 by the authors. Licensee MDPI, Basel, Switzerland This article is an open access article distributed under the terms and conditions of the Creative Commons Attribution (CC BY) license (https:/ / creativecommons.org/licenses/by/ $4.0 /)$.

\begin{abstract}
The effect of limonoids and spermine (Spm) extracted from yuzu (Citrus junos) seeds on the gut and the brain in a mouse model with Sandhoff disease (SD) was investigated. Wild-type and SD mice were fed a normal diet, or a diet supplemented with limonoid, Spm, or limonoid + Spm for 14-18 weeks, and then 16S rRNA gene amplicon sequencing with extracted DNA from their feces was executed. For SD control mice, intestinal microbiota was mostly composed of Lactobacillus and linked to dysbiosis. For SD and wild-type mice fed with limonoids + Spm or limonoids alone, intestinal microbiota was rich in mucin-degrading bacteria, including Bacteroidetes, Verrucomicrobia, and Firmicutes, and displayed a higher production of short-chain fatty acids and immunoglobulin A. Additionally, SD mice fed with limonoids + Spm or limonoids alone had less inflammation in hypothalamic tissues and displayed a greater number of neurons. Administration of limonoids and/or Spm improved the proportions of beneficial intestinal microbiota to host health and reduced neuronal degeneration in SD mice. Yuzu seed limonoids and Spermine may help to maintain the homeostasis of intestinal microbiota and hypothalamic tissue in the SD mouse model.
\end{abstract}

Keywords: Sandhoff disease; yuzu (Citrus junos); limonoids; spermine; intestinal microbiota; nextgeneration sequencing; short-chain fatty acids; immunoglobulin A

\section{Introduction}

Lysosomal storage disorders are progressive, single-gene disorders that are characterized by reduced enzyme activity and the accumulation of toxins in cells [1]. Sandhoff disease (SD) is one of a lysosomal storage disorder characterized by the absence of $\beta$-hexosaminidase and accumulate of GM2 ganglioside and related glycolipids GA2 in the central nervous system [2-5]. The glycolipid storage causes severe neurodegeneration through a poorly understood pathogenic mechanism. In SD mice models, extensive oxidative damage has been observed within the caudal regions in the brain [6,7]. No cure for SD has yet been found.

Our team previously demonstrated that treatment with limonoids or spermine (Spm) from yuzu seeds increased survival in SD mice [1]. Recent investigations on the benefits of limonoids or Spm as natural compounds have revealed that they have antitumor, antiinflammatory, and antioxidant properties [8-10], with the Spm notably implicated in 
maintaining the intestinal mucosal barrier [11]. Although elucidation of the underlying mechanism currently lingers, we consider degeneration of the nervous system to be rooted in oxidative stress and inflammation. Given that diet is well known for moderating these phenomena, consuming limonoids, and spermine (Spm), may be effective at combatting or minimizing neurological damage.

Several studies have shown that bilateral signals between the brain and intestine help to maintain homeostasis within the body and contribute to longevity [12-15]. Approximately 1000 species and 100 trillion bacteria are present in the human gastrointestinal tract [16], and it is clear that these bacteria play important roles in energy uptake from ingested food $[17,18]$. The microbiota has been recognized to play a role in human disease, including metabolic [19-22], inflammatory [23-25], and neurodegenerative disorders [26-28] and the mechanisms by which these microorganisms contribute to host health [29].

Gut microbiome metabolites include short-chain fatty acids (SCFAs), which are a result of intestinal bacterial fermentation of dietary fibers and polysaccharides. A schematic of intestinal SCFA production in humans is shown in Figure $1[30,31]$. The most abundant phyla in the intestine are Bacteroidetes and Firmicutes, with members of Bacteroidetes mainly producing acetate and propionate and those of Firmicutes producing butyrate [32,33]. These intestinal bacterial metabolites have emerged as the quintessential effectors mediating the impact of the microbiome on human or animal physiology [34-36]. SCFAs also have been seen to specifically alter hematopoiesis, promote immunoglobulin $\mathrm{A}(\mathrm{Ig} \mathrm{A})$ responses [37], alter $\mathrm{T}$ cell homeostasis [38,39], and promote neurogenesis [40]. The potential therapeutic role of SCFAs is also being examined with respect to the gut-brain axis, such as Parkinson's, autism, and schizophrenia [12-15]. It is plausible that this gut-brain axis in SD may function by strengthening the production of intestinal microbiota metabolites in SD mice by treating with limonoids and Spm.

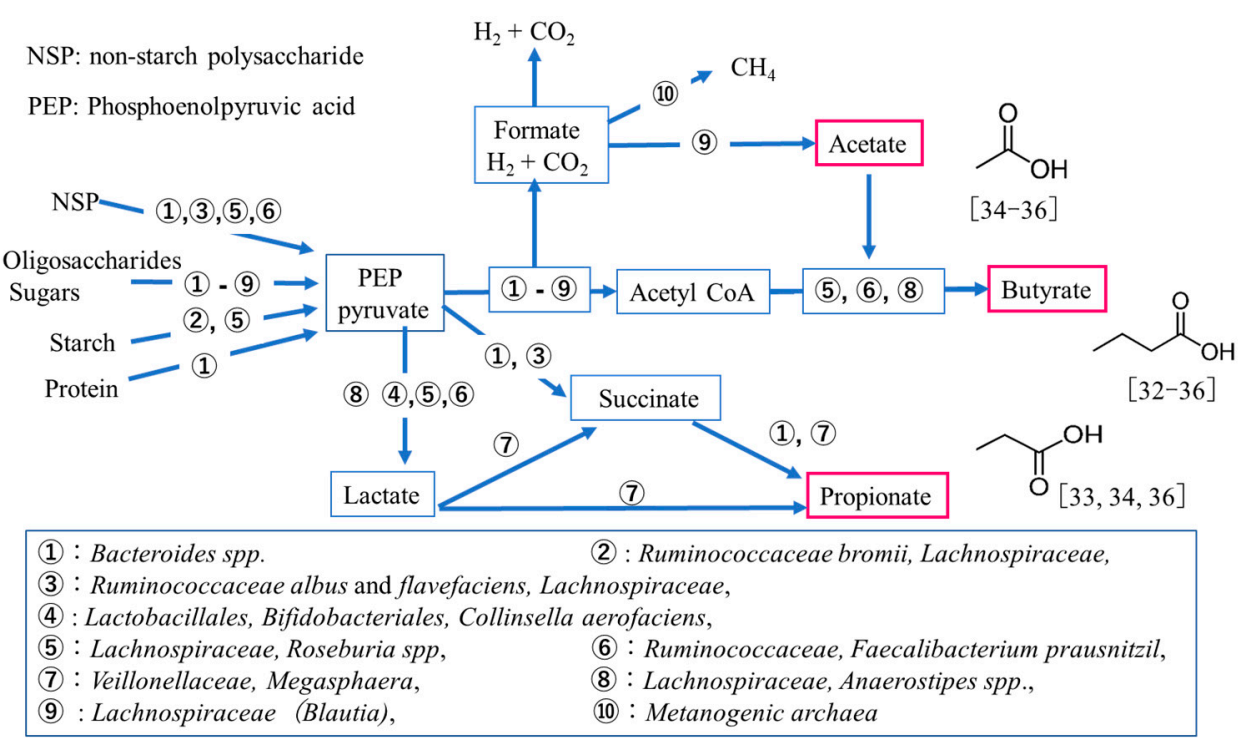

Figure 1. Schematic of intestinal short-chain fatty acid production in human colonic bacteria [30-36].

Hence, for this investigation, we aimed to examine the composition of intestinal microbiota in SD mice determined by $16 \mathrm{~S}$ rRNA next-generation sequencing. Correlations of production among microbiota, SCFAs, and IgA were analyzed using SD mice feces. It was investigated the impact of supplementation with limonoids or Spm from yuzu seed extracts on brain lesions, and the lifespan of SD mice.

\section{Materials and Methods}

\subsection{Materials}

The limonoids used in the experiments was extracted and purified from yuzu seed as described in a previous study [41]. Briefly, yuzu seeds were purchased from Kyoto 
Mizuo (Japan), and a limonoid mixture consisted of deacetylnomilin (105 $\mathrm{mg} \mathrm{g}^{-1}$ of dry seeds), limonin ( $95 \mathrm{mg} \mathrm{g}^{-1}$ of dry seeds), nomilin (115 mg g ${ }^{-1}$ of dry seeds), and obacnone (17 $\mathrm{mg} \mathrm{g}^{-1}$ of dry seeds) was extracted and purified.

Determination of the limonoids components and yuzu seed oil was performed by HPLC-MS and GC analysis as described previously $[1,41]$. Both analyses were conducted using a Shimadzu system (Kyoto, Japan). All standard analytical-grade or extra-pure reagents were purchased from Wako Pure Chemicals Company Ltd. (Osaka, Japan).

\subsection{SD Mouse Model and Dietary Supplementation with Limonoids and Spm}

All mice used in this study were bred and housed under standard non-sterile conditions. All mice including wild-type mice (WT mice) were offspring derived from a pair of Hexa + / - , Hexb + / - mice kindly provided by Richard L. Proia, National Institutes of Health (NIH), Bethesda, MD, USA. Homozygous Hexb knockout mice (Hexb - / -); SD model mice (Hexb - / - mice; C57BL / 6×129/Sv background) and WT mice (Hexb $+/+$ mice) were bred in a closed colony over 30 generations to inbreed for C57BL/6- and 129/Sv-derived genes [20]. SD model mice ( $n=196$ : male; $n=143$, female; $n=53$ ) were randomly categorized into four groups (control SD mice; $n=101$, SD mice fed with limonoids + Spm; $n=35$, SD mice fed with limonoids alone; $n=30$, or SD mice fed with Spm alone; $n=30)$. WT mice $(n=30$, male; 21 , female; 9$)$ were randomly categorized into three groups (control WT mice, WT mice fed with limonoids + Spm or limonoids alone; $n=10$ /group, each). A humane endpoint was applied when SD mice became moribund and no longer able to right themselves within $30 \mathrm{~s}$ of being laid on their side.

Mice were fed a normal diet or a diet supplemented with limonoid, Spm, or limonoid + Spm from 1 month of age until approximately 14-18 weeks of age when the animals died, according to a method reported previously [1]. Briefly, limonoids (6 mg) were dissolved in yuzu seed oil $(1 \mathrm{~mL})$ and sprinkled on mouse chow, and Spm (SigmaAldrich, St. Louis, MO, USA) was diluted in drinking water $\left(0.5 \mathrm{mg} \mathrm{mL}^{-1}\right)$ to achieve an administration dose of $0.18-0.20 \mathrm{mg} \mathrm{g}^{-1}$ of body weight day ${ }^{-1}$. Kaplan-Meier survival analysis for SD mice was performed using the statistical software Easy R (EZR) [42].

\subsection{Histopathological Analysis of Brain Tissues}

Histopathological findings pertaining to the thalamus from control SD mice aged 14-15 weeks were compared with those of treatment SD mice at 16-18 weeks, because of survival extended by limonoids + Spm administration. Formalin-fixed brains were embedded in paraffin, cut into $6 \mu \mathrm{m}$ sections, and stained with hematoxylin and eosin. The number of neurons was separately counted in the different four fields of the thalamus at $400 \times$ magnification (field size $=0.66 \mathrm{~mm}^{2}$ ). The average of the 4 values obtained in each region was calculated for each mouse, and the total number of neurons remaining in the measured fields is presented as the percentage of the total number of neurons.

\subsection{Extraction of DNA from Microbiota in Feces}

The fecal samples (10-20 mg) were collected until 14-18 weeks of age and suspended in a GTC (4 M guanidium thiocyanate, $100 \mathrm{mM}$ Tris- $\mathrm{HCl}(\mathrm{pH} 9.0)$, and $40 \mathrm{mM}$ EDTA ( $\mathrm{pH}$ 8.0)) solution and then homogenized in Lysing Matrix E (MP-Biomedicals, Santa Ana, CA, USA) using a FastPrep FP120 (Thermo Savant, Waltham, MA, USA). Thereafter, DNA (300-360 $\mathrm{ng} \mathrm{mL}^{-1}$ ) was extracted from a bead-treated suspension using a phenolchloroform extraction method and was purified with the FastGeneT Gel/PCR Extraction Kit (NIPPON Genetics Co, Ltd., Tokyo, Japan). All samples were stored at $-80^{\circ} \mathrm{C}$ until further analysis.

\subsection{Intestinal Microbiome Analysis: $16 S$ rRNA Amplicon Sequencing Library Preparation}

The Illumina protocol 16S Metagenomic Sequencing Library Preparation, Preparing 16S Ribosomal RNA (v4), Gene Amplicons for the Illumina Miseq/MiniSeq System (\#15044223JPN Rev. B) was used to construct 16S ribosomal RNA amplicons for the Illumina 
MiniSeq system (San Diego, CA, USA). The variable V4 regions of 16S rRNA were amplified from bacterial DNA in the feces. PCR was performed using the $16 \mathrm{~S}$ amplicon PCR forward primer (5'-TCGTCGGCAGCGTCAGATGTGTATAAGAGACAGGTGYCAGCMGCCGCGG TAA- $\left.3^{\prime}\right)$ and reverse primer (5'-GTCTCGTGGGCTCGGAGATGTGTATAAGAGACAGGGA CTACHVGGGTWTCTAAT-3'), which were synthesized by Hokkaido System Science Co., Ltd. (Hokkaido, Japan) as the most promising bacterial primer pair. Illumina adapter overhang nucleotide sequences were added at the $5^{\prime}$-end of both primers. Each $25 \mu \mathrm{L}$ reaction mixture contained $2.5 \mu \mathrm{L}$ microbial DNA $\left(5 \mathrm{ng} \mu \mathrm{L}^{-1}\right), 5 \mu \mathrm{L}$ of each primer $(1 \mu \mathrm{M})$, and $12.5 \mu \mathrm{L}$ of $2 \times$ KAPA HiFi HotStart Ready Mix (Kapa Biosystems Ltd., London, UK). A no-template control, in which nuclease-free water was added instead of bacterial DNA, and a negative control, which only contained the extraction from the sample and the stool lysis buffer (ASL buffer), were included in the PCR. The following PCR conditions were used: initial denaturation $\left(95^{\circ} \mathrm{C}\right.$ for $\left.3 \mathrm{~min}\right), 25$ cycles consisting of denaturation $\left(95^{\circ} \mathrm{C}\right.$ for $30 \mathrm{~s})$, annealing $\left(55^{\circ} \mathrm{C}\right.$ for $\left.30 \mathrm{~s}\right)$, extension $\left(72{ }^{\circ} \mathrm{C}\right.$ for $\left.3 \mathrm{~min}\right)$, a final extension step $\left(72{ }^{\circ} \mathrm{C}\right.$ for $5 \mathrm{~min}$ ), and a hold at $4{ }^{\circ} \mathrm{C}$. The resulting PCR products were run on the Agilent 2100 Bioanalyzer (Agilent Technologies, Santa Clara, CA, USA) to verify their sizes, and then they were purified primers and primer dimers using the Agencourt AMPure XP Kit (Beckman Coulter Genomics, Stortford, UK). Dual indices and Illumina sequencing adapters (P5 and P7) were attached to the amplicons using the Nextera XT Index Kit (Illumina) to construct the final libraries. Index PCR was conducted with $50 \mu \mathrm{L}$ reaction mixtures that contained $5 \mu \mathrm{L}$ of DNA, $5 \mu \mathrm{L}$ of Nextera XT Index Primer, $1.5 \mu \mathrm{L}$ of Nextera XT Index Primer, $2.25 \mu \mathrm{L}$ of $2 \times$ KAPA Hifi HotStart Ready Mix (Kapa Biosystems Ltd.), and $10 \mu \mathrm{L}$ of nuclease-free water. The following PCR conditions were used: initial denaturation $\left(95^{\circ} \mathrm{C}\right.$ for $\left.3 \mathrm{~min}\right)$, eight cycles of denaturation $\left(95^{\circ} \mathrm{C}\right.$ for $\left.30 \mathrm{~s}\right)$, annealing $\left(55^{\circ} \mathrm{C}\right.$ for $\left.30 \mathrm{~s}\right)$, extension $\left(72^{\circ} \mathrm{C}\right.$ for $30 \mathrm{~s}$ ), a final extension step $\left(72^{\circ} \mathrm{C}\right.$ for $5 \mathrm{~min}$ ), and a hold at $4{ }^{\circ} \mathrm{C}$. Before quantification, the libraries were cleaned using AMPure XP beads (Beckman Coulter Genomics) and amplicon size was verified using the Agilent 2100 Bioanalyzer (Agilent Technologies). All libraries were pooled in equimolar amounts, denatured, and diluted to $1.5 \mathrm{pM}$ before loading onto the MiniSeq flow cell and sequencing on the Illumina MiniSeq platform (Illumina, San Diego, CA, USA).

\subsection{Microbiota Analysis of Sequencing Data}

The raw sequencing files from both amplicon primers were processed using the QIIME 2 pipeline (https: / / docs.qiime2.org (accessed on 3 July 2019), ver. 2019.7). Preprocessed sequencing reads were used plugins. "Demux" https: / github.com/ qiime2/ q2-demux accessed on 3 July 2019) to import the demultiplexed paired-end sequencing reads and create the "artifact" file (i.e., the qiime2 data format required for subsequent analyses). The "dada2" plugin [43] was applied using the default parameter settings for quality and chimera filtering to trim primers, truncate forward and reverse reads, and collapse reads into representative sequences (i.e., amplicon sequence variants, ASVs). Taxonomy for these ASVs was assigned using the SILVA132 database (https: / / www.arb-silva.de/ documentation/release-132/e_blackstone@me.com (accessed on 13 December 2017)) and "feature-classifier" plugin (<https:/ / github.com/ qiime2/ q2-feature-classifier> (accessed on 13 December 2017)) with the "fit-classifier-sklearn" method. The taxon summary produced bar plots (<https:/ / github.com/qiime2/q2-taxa> (accessed on 13 December 2017)) according to the sample groupings.

\subsection{Quantitative Analysis of Short-Chain Fatty Acids (SCFAs) in Feces}

The measurement samples of the fecal SCFA content were collected from SD and WT mice at $12-14$ weeks of age. The collected feces were stored below $-80{ }^{\circ} \mathrm{C}$. Analysis of SCFAs was performed as previously described [23]. Briefly, $100 \mathrm{mg}$ of feces were mixed with $900 \mathrm{mg}$ of $0.5 \%$ phosphoric acid solution and then heated at $85^{\circ} \mathrm{C}$ for $15 \mathrm{~min}$. After crushing and cooling the sample, the supernatant was obtained by centrifugation at $14,000 \times g$ for $10 \mathrm{~min}$, mixed with an equal volume of ethyl acetate, and then centrifuged 
again at $14,000 \times g$ for $10 \mathrm{~min}$. The ethyl acetate layer was removed, and an internal standard (4-methylvaleric acid) was added. The fecal SCFAs were measured using flame ionization detection (7890 B Gas Chromatograph, Agilent Technologies, Santa Clara, CA, USA) and the internal standard method to determine the proportions of acetic acid, propionic acid, butyric acid, and valeric acid.

\subsection{Quantitative Analysis of IgA in Feces}

The measurement samples of the fecal IgA content were collected from SD and WT mice at 12-14 weeks of age. The collected feces were stored below $-80{ }^{\circ} \mathrm{C}$. The measurement sample of the fecal IgA content was prepared by adding PBS with $10 \mu \mathrm{L}$ of a P8340 protease inhibitor cocktail (Sigma-Aldrich) at a ratio of $1 \mathrm{~mL}$ to the mouse feces $0.1 \mathrm{~g}$ and then vortexed and centrifuged at $16,000 \times g$ for $10 \mathrm{~min}$. The fecal IgA content was determined using the E90-103 Mouse IgA ELISA Quantitation Kit (Bethyl Laboratories, Montgomery, TX, USA) and measured on a plate reader (Multiskan FC; Thermo Scientific) at a wavelength of $450 \mathrm{~nm}$.

\subsection{Statistical Analysis}

Kaplan-Meier survival analysis was performed using the statistical software Easy R(EZR) [42]. Data of Kaplan-Meier survival analysis are expressed as mean \pm standard error (S.E.). To evaluate significant differences in the relative abundance of bacterial populations, the Kruskal-Wallis test for multiple pairwise comparisons was performed. To conduct comparisons with other experimental parameters, CSV data on bacterial taxonomy was exported from QIIME2 (f taxa-bar-plots.qzv). Continuous parametric data were compared using one-way analysis of variance followed by Tukey's post-hoc analysis. Unpaired observations were analyzed using a one-sided Student's $t$-test. The significance threshold was set at $p<0.05$. Data are expressed as mean \pm standard deviation (S.D.). The correlation between the variables of the measured data was analyzed using Pearson's product-moment correlation coefficient.

\section{Results}

\subsection{Survival Rates of SD Mice Consuming Limonoids and/or Spm}

SD control mice had a mean life span of $105 \pm 0.25$ (mean \pm S.E.) days. Figure 2 shows that treatment with either limonoids or Spm starting at 4 weeks of age extended survival to $114 \pm 0.61$ or $111 \pm 0.50$ (mean \pm S.E.) days, respectively, and resulted in a $5 \%$ to $10 \%$ increase in life span $(p<0.001)$. Treatment with limonoids + Spm starting at 4 weeks of age extended survival to $118 \pm 0.57$ (mean \pm S.E.) days and resulted in a $12 \%$ increase in life span $(p<0.001)$. Compared with the SD control mice, the survival rates for all treatment groups were significantly different $(p<0.001)$.
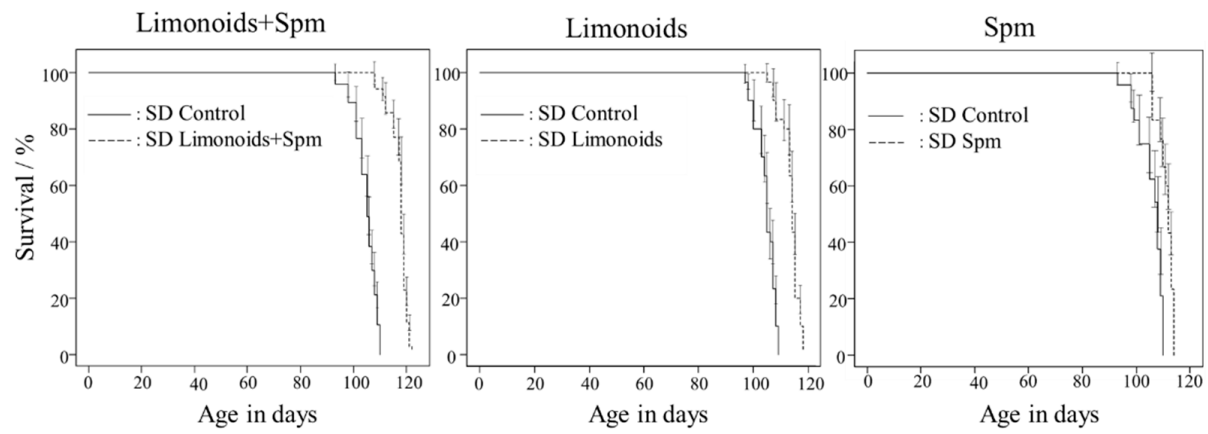

Figure 2. Survival curves for mice with Sandhoff disease fed with limonoids + Spm, limonoids alone, or Spm alone. Compared with the control group, survival rates were significantly different for all treatment groups: control $(p<0.001 ; n=101)$, limonoids + Spm $(p<0.001 ; n=35)$, limonoids $(p<0.001 ; n=30)$, or Spm $(p<0.001 ; n=30)$. Data are expressed as mean \pm S.E. of the mean. 


\subsection{Histopathological Analysis of Brain Tissue}

Figure 3A shows that histopathological examination of thalamic samples from SD mice demonstrated typical gangliosidosis and inflammatory/autoimmune disease (https: / / rarediseases.info.nih.gov/diseases/7604/sandhoff-disease (accessed on 7 March 2021)) as characterized by fat accumulation, granulovacuolar degeneration, rod-shaped microglia, and neuronal inflammation, as outlined by the Tokyo Metropolitan Institute for Medical Science (https: / /igakuken.or.jp / (accessed on 7 March 2021)). Mice fed with limonoids + Spm not only exhibited a decrease in these characteristic histopathological degenerations that was consistent with previous studies on mice fed with limonoids or Spm [1], but they also experienced minimal degeneration of the vacuoles, Purkinje cells, and the granular layer of the cerebellum. The number of neurons in the thalamus and midbrains in SD mice fed with limonoid and Spm were 1.3-fold $(p<0.01)$ and 1.5-fold $(p<0.001)$ higher, respectively, than those in SD control mice (Figure $3 b)$.

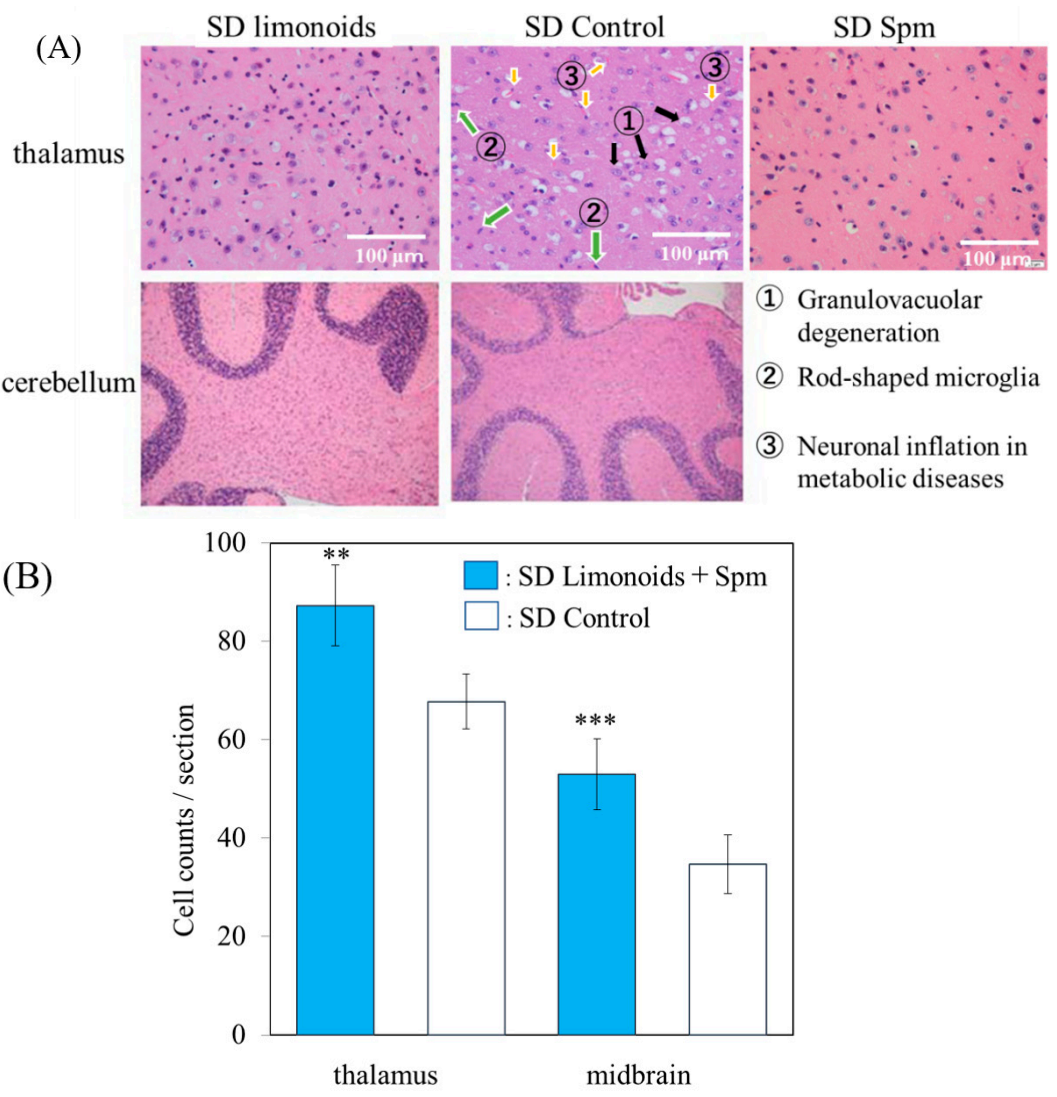

Figure 3. Histopathology of brain tissues for mice with Sandhoff disease (SD) fed with limonoids and Spm. (A) H\&E staining of thalamic (original magnification: $\times 400$, field size; $0.66 \mathrm{~mm}^{2}$ ) and cerebellum sections obtained from SD mice fed with limonoids, Spm or a normal diet (SD controls). The sections show enlarged cells with ganglioside storage. (B) Number of neurons in the thalamus and midbrain for SD mice fed with limonoids + Spm or control SD mice. Values represent means \pm S.D. $(n=4)$. Data onto a bar graph are plotted in comparison to the controls for clarity; ${ }^{* *} p \leq 0.01 ;{ }^{* *} p \leq 0.001$.

\subsection{Composition of Fecal Microbiota in SD and Wild Control (WT) Mice}

Figure $4 \mathrm{~A}$ shows that the phylum to genus taxonomic classifications, as determined by 16S rRNA gene amplicon sequencing, was quite different for the SD and WT mice. In the feces Bacteroidetes and Firmicutes accounted for most of the phylum, and the abundances of Firmicutes and Bacteroidales were smaller and larger, respectively, in feces for SD and WT mice fed with limonoids + Spm and limonoids alone. Figure 4B shows that the Firmicutes/Bacteroidetes ratio in the SD and WT control mice was high and nearly the same $(\mathrm{SD}, 6.75 \pm 3.34 ; \mathrm{WT}, 7.39 \pm 3.57)$. This ratio was significantly reduced in SD and WT mice 
fed with limonoids + Spm (SD, $2.60 \pm 1.11 ; \mathrm{WT}, 0.789 \pm 0.159 ; p<0.05$, compared with the respective control group) or those fed with limonoids alone (SD, $0.587 \pm 0.107$; WT, $1.37 \pm 0.159 ; p<0.05)$.

(A)

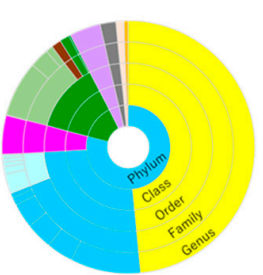

SD Control

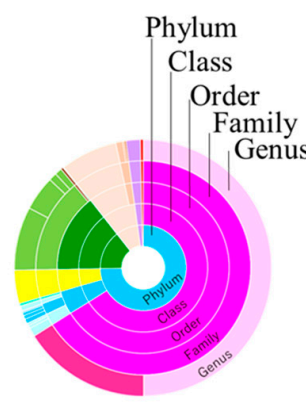

WT Control

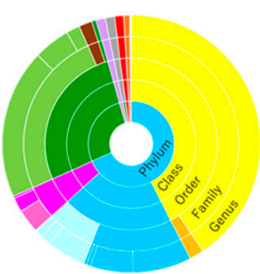

SD Limonoids + Spm

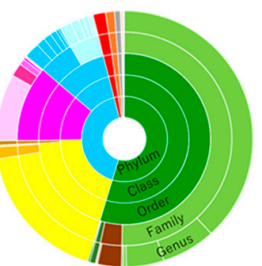

WT Limonoids + Spm

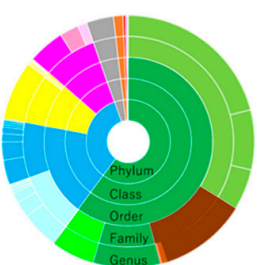

SD Limonoids

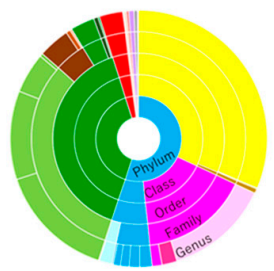

WT Limonoids

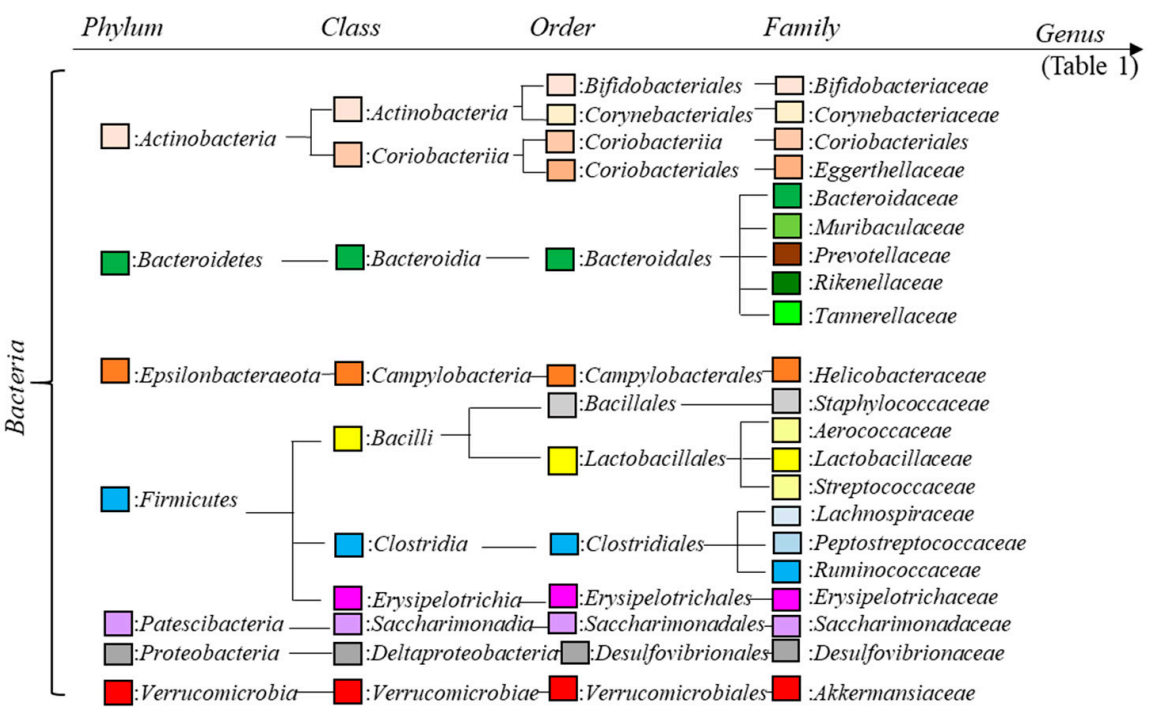

(B)

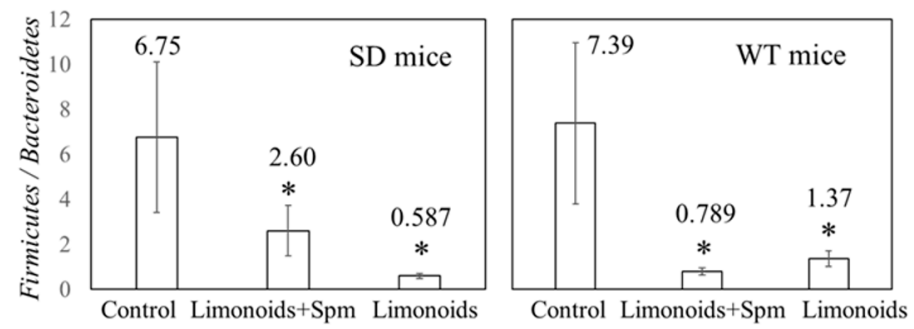

Figure 4. Estimated ratios (\%) of phylum-genus taxonomic categories identified by genomic analysis of 16S rRNA in feces of mice aged 12-14 weeks (A), and relative abundance Firmicutes/Bacteroidetes ratio (B). Values represent mean \pm S.D. SD and WT mice were treated at 12-14 weeks of age (WT mice; $n=9$ /each group, $\mathrm{SD}$ mice; $n=15$ /each group). Data are plotted in comparison to the controls for clarity; ${ }^{*} \leq 0.05$. SD, Sandhoff disease; WT, wild-type. 
Figure 5 and Table 1 present a comparison of the relative abundance of bacterial (\%) at the genus level between SD and WT control mice and mice fed with limonoids + Spm. The abundance of Lactobacillus was similar in the SD control mice and SD mice fed with limonoids + Spm $(47 \% \pm 11 \%$ vs. $39 \% \pm 12 \%)$; SD mice fed with limonoids alone displayed a lower abundance of Lactobacillus $(7.4 \% \pm 1.8 \%)$. Moreover, the abundance of microbiota classified in the phylum Firmicutes, order Clostridiales, and genus Ruminococcaceae significantly decreased in SD mice fed with limonoids + Spm or limonoids compared with SD control mice. By contrast, the abundance of microbiota classified in the phylum Firmicutes, order Clostridiales, and genus Lachnospiraceae, as well as that of microbiota classified in the phylum Bacteroidetes, order Bacteroidales, and genera Muribaculaceae, Parabacteroroides, Alloprebotella, and Bacteroides, was significantly increased in the SD mice fed with limonoids + Spm or limonoids.
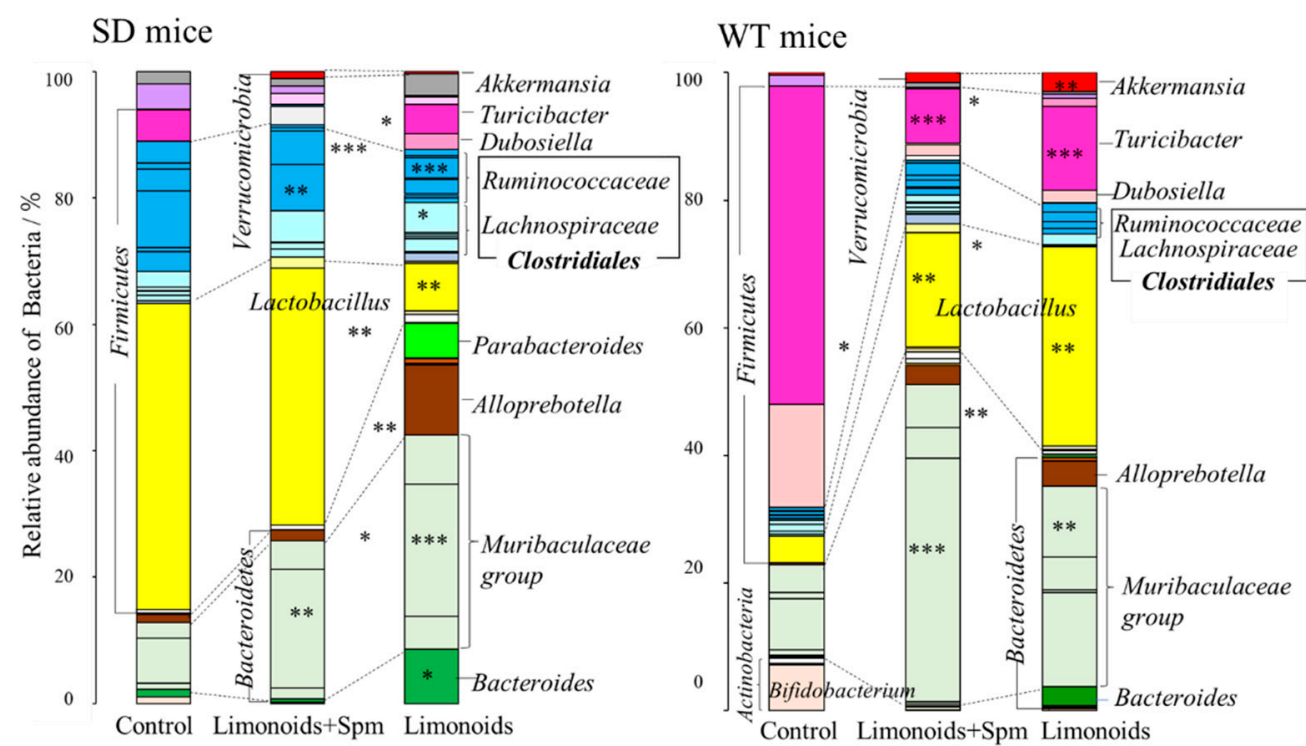

Figure 5. Estimated ratios (\%) of taxonomic categories at the genus level were identified according to genomic analysis of 16S rRNA in the feces of SD or WT mice aged 12-14 weeks (WT mice; $n=9$ /each group, SD mice; $n=15$ /each group). Values represent means \pm S.D. Data onto a bar graph are plotted in comparison to the controls for clarity; $p \leq 0.05 ;{ }^{* *} p \leq 0.01 ;{ }^{* *} p \leq 0.001$. SD, Sandhoff disease; WT, wild-type.

Although the Firmicutes / Bacteroidetes ratio was similar at the phylum level, WT mice had different microbiota composition than SD mice at the genus level. In WT control mice, the abundances of Turicibacter $(50 \% \pm 6.3 \%)$ and Dubosiella $(23.29 \% \pm 4.90 \%)$ in the Erysipelotrichaceae family (Firmicutes) and Bifidobacterium $(7.2 \% \pm 0.026 \%)$ in the Actinobacteria phylum significantly increased. Dubosiella was not listed in the 2017 genomic database, which was a recently proposed novel genus [44]. The members of Erysipelotrichaceae family occupied the majority the abundance of microbiota in feces from WT control mice. It is reported that the abundances of members of Erysipelotrichaceae family increased due to fat accumulation from normal diet in mice [1,42].

In contrast to SD mice, WT mice showed an increased abundance of Lactobacillus in the following order: control $(4.2 \% \pm 1.5 \%)<$ limonoids + Spm $(18 \% \pm 5.7 \%)<$ limonoids alone $(31 \% \pm 9.8 \%)$. In both SD and WT mice, the Verrucomicrobia phylum (Akkermansia genus) was observed in microbiota mainly from mice fed with limonoids + Spm or limonoids alone. An intriguing observation was that there was a higher abundance of mucin-degrading bacteria in mice fed with limonoids alone. Moreover, various bacteria involved in mucin metabolism for intestinal epithelial cells were present, including Bacteroides, Ruminococcus, Prevotella, and Desulfofibrio. 
Table 1. Comparison of the relative abundance of bacterial (\%) in feces from SD or WT mice fed with a normal diet (control), limonoids + Spm or limonoids alone.

\section{Relative Abundance of Bacterial (\%)}

\section{Genus Classification}

SD Mice

WT Mice

\begin{tabular}{|c|c|c|c|c|c|c|}
\hline & Control & Limonoids + Spm & Limonoids & Control & Limonoids + Spm & Limonoids \\
\hline \multicolumn{7}{|c|}{ No. Firmicutes-Clostridiales-Lachnospiraceae family } \\
\hline 1. Lachnoclostridium & $0.33 \pm 0.15$ & nd. & $1.3 \pm 0.79 *$ & nd. & $1.5 \pm 0.58$ & nd. \\
\hline $\begin{array}{l}\text { 2. Lachnospiraceae FCSO20 } \\
\text { group }\end{array}$ & $0.91 \pm 0.42$ & $1.2 \pm 1.0$ & $0.22 \pm 0.27$ & $0.34 \pm 0.27$ & $0.10 \pm 0.08$ & $0.13 \pm 0.10$ \\
\hline $\begin{array}{l}\text { 3. Lachnospiraceae } \\
\text { NK4A136 group }\end{array}$ & $0.54 \pm 0.15$ & $0.84 \pm 0.96$ & $2.1 \pm 1.1$ * & nd. & $0.34 \pm 0.20$ & nd. \\
\hline $\begin{array}{l}\text { 4. Lachnospiraceae } \\
\text { UCG-004 }\end{array}$ & nd. & nd. & $0.26 \pm 0.31$ & nd. & nd. & nd. \\
\hline $\begin{array}{l}\text { 5. Lachnospiraceae } \\
\text { UCG-006 }\end{array}$ & $0.19 \pm 0.14$ & nd. & $0.31 \pm 0.38$ & nd. & $0.58 \pm 0.48$ & nd. \\
\hline $\begin{array}{l}\text { 6. Uncultured } \\
\text { (Lachnospiraceae) }\end{array}$ & $0.43 \pm 0.31$ & $0.16 \pm 0.22$ & $0.36 \pm 0.44$ & $0.37 \pm 0.30$ & $0.26 \pm 0.21$ & nd. \\
\hline 7. Lachnospiraceae & $2.5 \pm 0.018$ & $4.8 \pm 1.1^{*}$ & $4.6 \pm 1.7^{*}$ & $1.1 \pm 0.51$ & $1.0 \pm 0.56$ & $1.6 \pm 0.94$ \\
\hline $\begin{array}{l}\text { 8. Eubacterium fissicatena } \\
\text { group }\end{array}$ & nd. & nd. & nd. & nd. & $0.64 \pm 0.52$ & nd. \\
\hline
\end{tabular}

\begin{tabular}{|c|c|c|c|c|c|c|}
\hline \multicolumn{7}{|c|}{ Firmicutes-Clostridiales-Peptostreptococcaceae family } \\
\hline 9. Romboutsia & nd. & nd. & nd. & $0.67 \pm 0.55$ & nd. & nd. \\
\hline 10. Peptostrepto- coccaceae & nd. & nd. & nd. & $0.34 \pm 0.28$ & nd. & nd. \\
\hline \multicolumn{7}{|c|}{ Firmicutes-Clostridiales-Ruminococcaceae family } \\
\hline 11. Ruminiclostridia- um 5 & $3.0 \pm 1.2$ & $7.0 \pm 3.2 * *$ & $0.81 \pm 0.68$ & $0.34 \pm 0.28$ & $1.1 \pm 0.34$ & $0.85 \pm 0.38$ \\
\hline 12. Rumini-clostridium 9 & $0.60 \pm 0.42$ & $0.34 \pm 0.41$ & nd. & nd. & $0.23 \pm 0.19$ & nd. \\
\hline $\begin{array}{l}\text { 13. Ruminococcaceae } \\
\text { UCG-009 }\end{array}$ & nd. & nd. & $0.22 \pm 0.27$ & nd. & nd. & nd. \\
\hline $\begin{array}{l}\text { 14. Ruminococcaceae } \\
\text { UCG-014 }\end{array}$ & $8.7 \pm 2.2$ & $5.1 \pm 2.9$ & $2.3 \pm 0.58$ & $0.09 \pm 0.08$ & $0.98 \pm 0.02$ & $1.1 \pm 0.10$ \\
\hline 15. Ruminococcus 1 & $3.3 \pm 1.2$ & $0.54 \pm 0.56$ & $0.062 \pm 0.07$ & $0.53 \pm 0.05$ & $0.75 \pm 0.61$ & $1.5 \pm 0.95$ \\
\hline $\begin{array}{c}\text { 16. UBA1819 } \\
\text { (Ruminococcaceae) }\end{array}$ & nd. & nd. & $0.18 \pm 0.22$ & nd. & nd. & nd. \\
\hline $\begin{array}{c}\text { 17. Eubacteriumcopro- } \\
\text { stanoligenes } \\
\text { group }\end{array}$ & $0.96 \pm 0.23$ & $0.35 \pm 0.39$ & $3.1 \pm 2.1$ & $0.17 \pm 0.05$ & $1.9 \pm 0.13$ & $1.3 \pm 0.43$ \\
\hline $\begin{array}{l}\text { 18. Uncultured } \\
\text { (Ruminococcaceae) }\end{array}$ & nd. & nd. & $0.29 \pm 0.20$ & nd. & nd. & $0.29 \pm 0.20$ \\
\hline 19. Ruminococcaceae & $3.3 \pm 1.2$ & nd. & $1.0 \pm 0.62$ & $0.49 \pm 0.12$ & $0.40 \pm 0.33$ & $0.19 \pm 0.07$ \\
\hline \multicolumn{7}{|c|}{ Firmicutes-Lactobacillales-Lactobacillaceae family } \\
\hline Lactobacillus & $47 \pm 11$ & $39 \pm 12$ & $7.4 \pm 1.8^{* *}$ & $4.2 \pm 1.5$ & $18 \pm 5.7^{* *}$ & $31 \pm 9.8^{* *}$ \\
\hline Lactococcus & nd. & $1.7 \pm 2.0$ & $0.30 \pm 0.37$ & nd. & $1.5 \pm 1.2$ & $0.19 \pm 0.16$ \\
\hline \multicolumn{7}{|c|}{ Firmicutes-Erysipelotrichales-Erysipelotrichaceae family } \\
\hline Candidatus Stoquefichus & nd. & $2.9 \pm 3.4$ & nd. & nd. & $0.78 \pm 0.33$ & nd. \\
\hline Dubosiella & nd. & nd. & $2.4 \pm 1.4$ & $16 \pm 1.9$ & $1.7 \pm 1.4^{* * *}$ & $1.9 \pm 1.5^{* * *}$ \\
\hline
\end{tabular}


Table 1. Cont.

\begin{tabular}{|c|c|c|c|c|c|c|}
\hline \multirow{3}{*}{ Genus Classification } & \multicolumn{6}{|c|}{ Relative Abundance of Bacterial (\%) } \\
\hline & \multicolumn{3}{|c|}{ SD Mice } & \multicolumn{3}{|c|}{ WT Mice } \\
\hline & Control & Limonoids + Spm & Limonoids & Control & Limonoids + Spm & Limonoids \\
\hline Erysipelatoclostridium & nd. & $0.28 \pm 0.39$ & nd. & nd. & $0.29 \pm 0.23$ & nd. \\
\hline Turicibacter & $4.8 \pm 1.9$ & nd. & $4.5 \pm 2.1$ & $50 \pm 6.3$ & $8.5 \pm 4.0^{* * *}$ & $13 \pm 6.2^{* * *}$ \\
\hline Erysipelotrichaceae & $0.06 \pm 0.04$ & $1.7 \pm 2.4$ & $1.2 \pm 0.92$ & nd. & $0.23 \pm 0.18$ & $1.3 \pm 0.55$ \\
\hline \multicolumn{7}{|c|}{ Patescibacteria-Saccharimonadales-Saccharimonadaceae family } \\
\hline Candidatus Saccharimonas & $3.8 \pm 2.7$ & $1.2 \pm 1.6$ & $0.22 \pm 0.27$ & $1.8 \pm 1.4$ & nd. & $0.68 \pm 0.16$ \\
\hline \multicolumn{7}{|c|}{ Proteobacteria-Desulfovibrionales-Desulfovibrionaceae family } \\
\hline Desulfovibrio & $1.9 \pm 0.53$ & $1.1 \pm 1.5$ & $3.4 \pm 3.9$ & nd. & $0.75 \pm 0.60$ & $0.38 \pm 0.03$ \\
\hline \multicolumn{7}{|c|}{ Verrucomicrobia-Verrucomicrobiales-Akkermansiaceae family } \\
\hline a Akkermansia & nd. & $1.1 \pm 1.3$ & $0.31 \pm 0.27$ & $0.37 \pm 0.30$ & $1.6 \pm 1.3^{*}$ & $3.0 \pm 2.0 * * *$ \\
\hline \multicolumn{7}{|c|}{ Bacteroidetes-Bacteroidales-Bacteroidaceae family } \\
\hline${ }^{a}$ Bacteroides & $1.2 \pm 0.076$ & $0.51 \pm 0.36$ & $8.4 \pm 4.5^{*}$ & $0.14 \pm 0.11$ & $0.21 \pm 0.13$ & $3.0 \pm 0.02$ \\
\hline \multicolumn{7}{|c|}{ Bacteroidetes-Bacteroidales-Muribaculaceae family } \\
\hline Muribaculum & $0.90 \pm 0.64$ & $1.6 \pm 2.3^{* *}$ & $5.1 \pm 5.8^{* * *}$ & $0.90 \pm 0.73$ & $0.35 \pm 0.26$ & $15 \pm 3.4^{* * *}$ \\
\hline $\begin{array}{c}\text { Uncultured } \\
\text { Bacteroidales bacterium }\end{array}$ & nd. & nd. & nd. & nd. & $0.26 \pm 0.09$ & nd. \\
\hline Uncultured Barnesiella sp. & nd. & nd. & nd. & nd. & nd. & $0.41 \pm 0.34$ \\
\hline Uncultured Bacterium & $6.9 \pm 2.7$ & $26 \pm 3.8^{* *}$ & $28 \pm 9.5^{* * *}$ & $8.0 \pm 5.5$ & $38 \pm 2.9^{* * *}$ & $5.1 \pm 0.53$ \\
\hline Uncultured organism & nd. & nd. & nd. & $1.0 \pm 0.82$ & $4.8 \pm 0.76$ & nd. \\
\hline Muribaculaceae & $2.4 \pm 0.097$ & $6.6 \pm 0.27$ & $7.5 \pm 2.3$ & $4.4 \pm 1.6$ & $6.8 \pm 0.22$ & $11 \pm 2.7^{* *}$ \\
\hline \multicolumn{7}{|c|}{ Bacteroidetes-Bacteroidales-Prevotellaceae family } \\
\hline${ }^{a}$ Alloprevotella & $1.2 \pm 0.37$ & $1.6 \pm 0.63$ & $11 \pm 2.7$ & $0.30 \pm 0.24$ & $3.0 \pm 0.56$ & $4.0 \pm 1.6$ \\
\hline a Paraprevotella & nd. & nd. & $0.18 \pm 0.11$ & nd. & $0.10 \pm 0.08$ & $0.53 \pm 0.34$ \\
\hline $\begin{array}{c}\text { a Prevotellaceae NK3B31 } \\
\text { group }\end{array}$ & nd. & nd. & $0.089 \pm 0.11$ & nd. & $0.17 \pm 0.14$ & nd. \\
\hline${ }^{a}$ Prevotellaceae & nd. & nd. & $0.65 \pm 0.80$ & nd. & nd. & $0.28 \pm 0.23$ \\
\hline \multicolumn{7}{|c|}{ Bacteroidetes-Bacteroidales-Tannerellaceae family } \\
\hline a Parabacteroides & nd. & nd. & $5.4 \pm 1.5$ & nd. & $0.73 \pm 0.57$ & $0.58 \pm 0.21$ \\
\hline \multicolumn{7}{|c|}{ Actinobacteria-Bifidobacteriales-Bifidobacteriaceae family } \\
\hline${ }^{a}$ Bifidobacterium & nd. & nd. & nd. & $7.2 \pm 0.03$ & nd. & nd. \\
\hline
\end{tabular}

Values represent mean \pm S.D. Data for treatment groups are plotted against that for controls; ${ }^{*} p \leq 0.05 ;{ }^{* *} p \leq 0.01 ;{ }^{* * *} p \leq 0.001$. SD, Sandhoff disease; WT, wild-type. Notes: nd, not detected; ${ }^{a}$ Mucolytic bacteria.

\subsection{SCFAs and IgA Productions in SD and WT Mice Feces}

Figure 6a shows SCFAs content $\left(\mu \mathrm{mol} \mathrm{g}^{-1}\right)$ in feces from SD and WT mice at 12-14 weeks of age. Production of acetic acid was highest among SD and WT mice fed with limonoids + Spm, production of butyric acid was highest among SD and WT mice fed with limonoids + Spm or limonoids alone, and production of propionic acid was similar across all groups. The reduction in SCFA content was the highest in SD and WT control mice. 


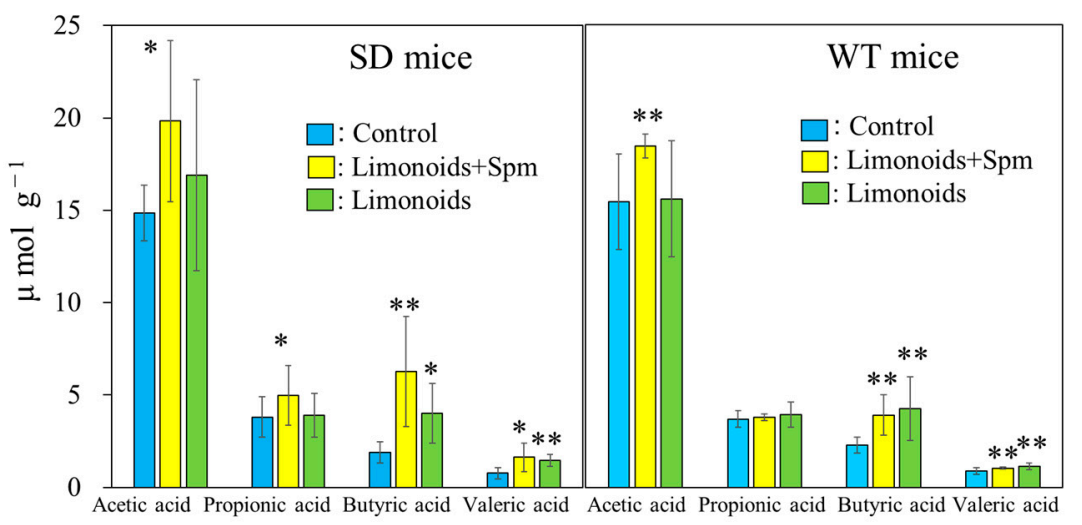

(a)

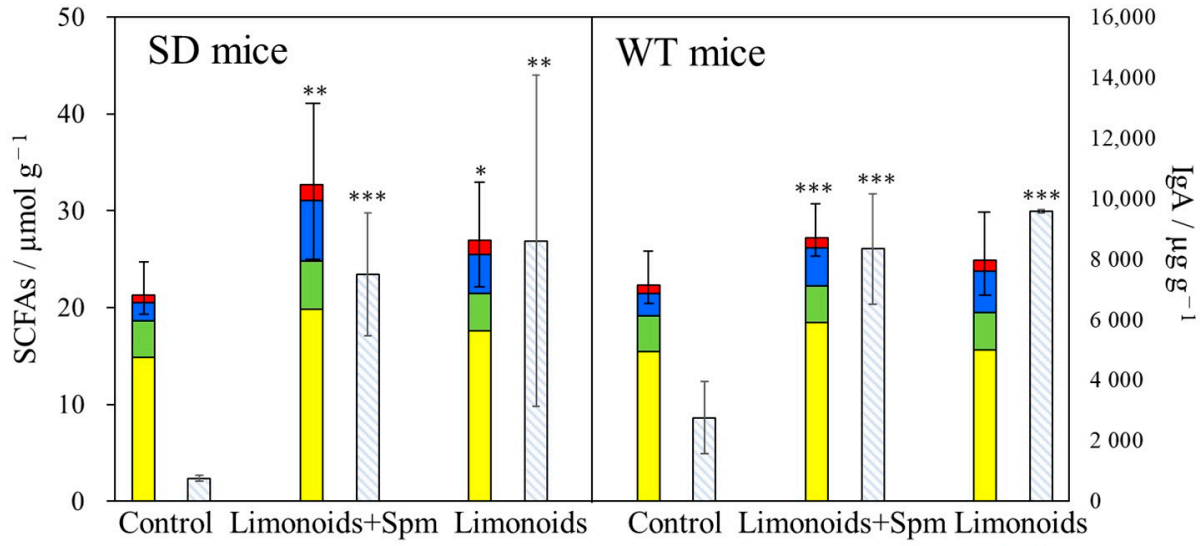

$\mathbb{N}$ :IgA, Total SCFAs ( $\square$ :Acetic acid, $\square$ : Propionic acid, $\square$ : Butyric acid, $\square$ : Valeric acid)

(b)

Figure 6. Short-chain fatty acid (SCFA) content $\left(\mu \mathrm{mol} \mathrm{g}^{-1}\right)(\mathbf{a})$ in feces from SD or WT mice (b) and comparison of immunoglobulin A (IgA) production $\left(\mu \mathrm{g} \mathrm{g}^{-1}\right)$ vs. total SCFA content. SD and WT mice were treated at $12-14$ weeks of age (WT mice; $n=9$ /each group, SD mice; $n=15$ /each group). Values represent means \pm S.D. Data onto a bar graph are plotted in comparison to the controls for clarity; ${ }^{*} p \leq 0.05 ;{ }^{* *} p \leq 0.01 ;{ }^{* *} p \leq 0.001$. The correlation coefficient between the levels of SCFAs and IgA, $r=0.52, p 0.05$. SD, Sandhoff disease; WT, wild-type.

Figure $6 \mathrm{~b}$ show the comparison of immunoglobulin A $(\operatorname{IgA})$ production $\left(\mu \mathrm{g} \mathrm{g}^{-1}\right) \mathrm{vs}$. total SCFA content in feces from SD or WT mice at 12-14 weeks of age. IgA production was significantly higher in mice fed with limonoids + Spm (SD, $7700 \pm 1241 \mu^{-1} \mathrm{~g}^{-1}$, $p<0.001$; WT, $\left.8492 \pm 1096 \mu \mathrm{g} \mathrm{g}^{-1}, p<0.001\right)$ or limonoids alone (SD, $8596 \pm 3160 \mu \mathrm{g} \mathrm{g}^{-1}$, $p<0.01$; WT, $\left.95611 \pm 48 \mu \mathrm{g} \mathrm{g}^{-1}, p<0.001\right)$ than in control mice (SD, $753 \pm 102 \mu \mathrm{g} \mathrm{g}^{-1}$; $\left.\mathrm{WT}, 2066 \pm 996 \mu \mathrm{g} \mathrm{g}^{-1}\right)$. The amounts of IgA production increased by fourfold to tenfold in mice fed with limonoids + Spm or limonoids alone than SD and WT control mice. A positive correlation was observed between the production levels of SCFAs and $\operatorname{IgA}, r=0.52$, $p<0.01$.

\subsection{Correlation between Limonoids and/or Spermine and the Clostridiales Group}

We found a significant difference SCFAs content in mice feces between SD or WT control mice and those that fed limonoids + Spm; in particular, butyric acid production increased in SD mice fed limonoids + Spm (Figure 6a). To identify intestinal microbiota that might be involved in butyric acid metabolism, we focused on bacteria belonging to the Clostridiales group. A significantly large relative abundance ratio of bacteria in the Clostridiales group was found in mice feces fed with limonoids + Spm or limonoids alone (Figure 7, red dashed line; Table 1, and Figure 8). 

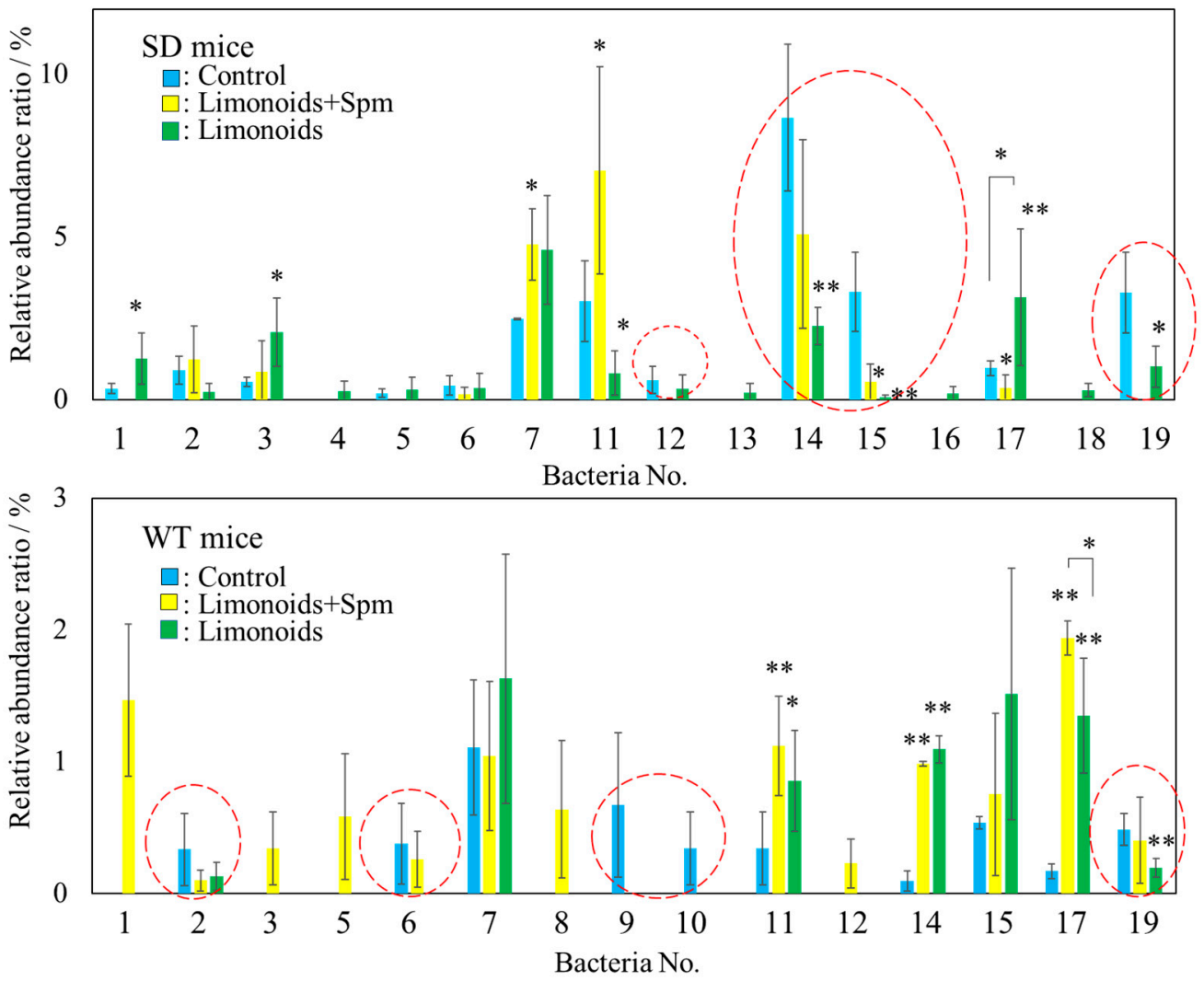

Figure 7. Comparison of the relative abundance (\%) of bacteria at the genus level belonging to the Clostridiales order in feces for SD or WT mice. The bacterial numbers in the figure correspond to the bacterial numbers listed in Table 1. Bacteria whose relative abundance ratio was suppressed by feeding limonoids + Spm or limonoids alone are surrounded by a red dashed line. Values represent mean \pm S.D. Data are plotted in comparison to the controls for clarity; ${ }^{*} p \leq 0.05 ;{ }^{* *} p \leq 0.01$. SD, Sandhoff disease; WT, wild-type.

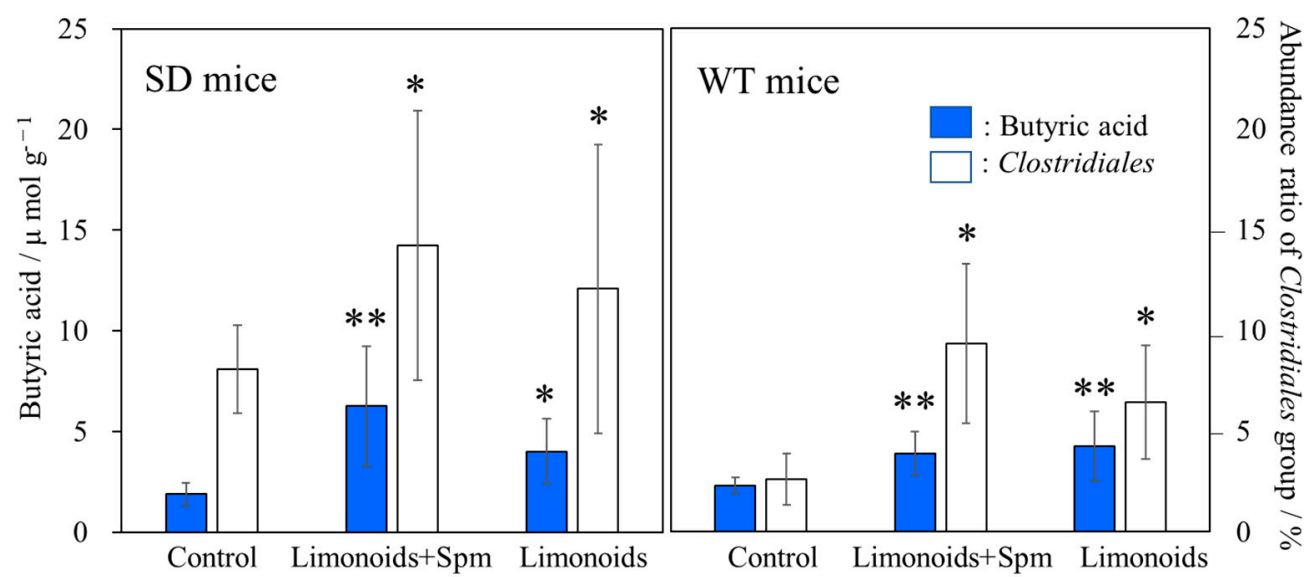

Figure 8. Comparison of the amount of butyric acid in feces from SD or WT mice $\left(\mu \mathrm{mol} \mathrm{g} \mathrm{g}^{-1}\right)$ and relative abundance (\%) of bacteria (Clostridiales groups) identified from Figure 7 as promoting butyric acid metabolism. Values represent mean \pm S.D. Data onto a bar graph are plotted in comparison to the controls for clarity; ${ }^{*} p \leq 0.05 ;{ }^{* *} p \leq 0.01$. The correlation coefficient between the relative abundance $(\%)$ of the Clostridiales groups and the amount of butyric acid, $r=0.72, p<0.01$. SD, Sandhoff disease; WT, wild-type.

We found that in SD mice fed with limonoids + Spm or limonoids alone, the abundance of Ruminiclostridium 9 (No. 12), Ruminococcaceae UCG 14 (No. 14), Ruminococcus 1 (No. 15), 
and Ruminococcaceae (No. 19) was significantly altered across the three groups of SD mice. Furthermore, SD mice fed with limonoids + Spm showed a significant increase in the levels of Ruminiclostridium 5 (No. 11) compared with SD control mice or those fed with limonoids alone. By contrast, the number of bacterial types of SD mice fed with limonoids alone increased $136 \%(p<0.001)$ vs. control or $120 \%(p<0.01)$ vs. limnoids + Spm. The members of the Clostridiales order were significantly different between WT control mice and mice fed with limonoids + Spm or limonoids alone, though nearly the same bacterial populations were identified in SD and WT mice fed with limonoids + Spm or limonoids alone. However, the abundance ratio of bacteria identified differed. The relative abundance ratio of Clostridiales in feces of SD or WT mice fed with limonoids + Spm increased 135\% $(p<0.001)$ vs. SD mice fed limonoids or $134 \%(p<0.05)$ vs. WT fed limonoids.

From Figure 7 and Table 1, the relative abundance ratio (\%) of the Clostridiales group bacteria identified as promoting butyric acid metabolism in the presence of limonoids $+\mathrm{Spm}$ or limonoids alone was compared with the amount of butyric acid measured in mouse feces $\left(\mu \mathrm{mol} \mathrm{g}^{-1}\right)$ (Figure 8). A positive correlation was shown between the abundance of bacteria belonging to the Clostridiales order and butyric acid production promoted by the consumption of limonoids + Spm or limonoids alone $(r=0.72, p<0.01)$. We found that the relative abundance ratio of the Clostridiales order group found in the feces of both SD and WT mice fed limonoids + Spm were larger than other mice.

\section{Discussion}

In the current study, we found that SD mice fed with limonoids, Spm, or limonoids + Spm extracted from yuzu seeds displayed a slower rate of disease progression compared with SD control mice. Noteworthily, the brains of SD mice fed with limonoids and Spm had less degeneration with inflammation, suggesting that limonoids and Spm suppress inflammation caused by glycolipid accumulation in the central nervous system.

The Firmicutes/Bacteroidetes ratio was similar in SD and WT control mice compared with the other groups; however, the microbiota at the genus level for SD control mice was composed of $47 \%$ Lactobacillus, whereas the WT control mice existed 50\% Turicibacter and 16\% Dubosiella belonging Erysipelotrichaceae family. It is reported that the increase in abundances of members of Erysipelotrichaceae family is due to fat accumulation from the normal diet in mice [1,42].

While there is generally known the mechanisms via which gut microbiota may mediate obesity, the identities of the bacteria that constitute an "obese microbiota" such as Erysipelotrichaceae have not yet been unequivocally established. The feature is that the Firmicutes / Bacteroidetes ratio increases as the obese microbiota increases [42,43]. This phenomenon was similarly confirmed in WT control mice. Actually, in SD control mice, Turicibacter existed only $4.8 \%$.

On the other hand, such extremely biased ratios of Lactobacillus in SD control mice may be implicated in dysbiosis, a condition in which microbiota diversity is reduced primarily because of antibiotic administration, unhealthy dietary intakes, infection, genetic abnormalities, and immune disorders [45]. Dysbiosis has also been reported to increase the permeability of epithelial cells in the small intestine [46], and ulcerations attributed to increased permeability of these cells can lead to intestinal inflammation via intestinal microbiota or their associated metabolites. Examples of such dysbiosis have been reported in the case of Parkinson's disease. In an analysis of intestinal microbiota from patients with Parkinson's disease and mouse model, amounts of Clostridium and Bacteroides were significantly lower and amounts of Lactobacillus were significantly higher compared with healthy counterparts, the ratios of these bacterial populations are reported as the prime indicants of dysbiosis in Parkinson's disease [47-50]. Furthermore, untreated patients with Parkinson's disease have increased colonic permeability, and that patients have a pathological expression of $\alpha$-synuclein in their colon. Even may initiate Parkinson's disease events through gut-derived, lipopolysaccharide-induced neuronal injury. It has been suggested that the intestinal plexus becomes abnormal and ultimately affects the 
central nervous system [47-51]. Although the mechanisms underlying increased intestinal permeability in dysbiosis remain elusive [52], such increased permeability will likely render intestinal neuronal cells sensitive to the intestinal microbiota.

In SD mice, supplementing the diet with limonoids + Spm or limonoids alone induced many changes in the relative abundance of bacterial species in the intestinal microbiota for SD mice. Importantly, these compounds alleviated intestinal dysbiosis by promoting the growth of Lachnospiraceae, Alloprevotella, Akkermansia, and Bacteroides, as well as suppressing the growth of Lactobacillus. While, in WT mice, supplementing the diet with limonoids + Spm or limonoids alone increased the diversity of the gut microbiome by suppressing the growth of Turicibacter and Dubossiella. Recently, Akkermansia has attracted attention as a genus that suppresses inflammation, improves insulin resistance [53], and modulates susceptibility to seizure in refractory epilepsy [54].

Akkermansia, Bacteroides, and Bifidobacterium are called mucolytic bacteria, because, they have dozens of glycosidases and peptidases, decompose mucin glycoproteins, and can use as their own nutrient source. Mucolytic bacteria (mucin-degrading bacterium) are a general term for bacteria that decompose gastrointestinal tract mucin and use it as a carbon source. Mucolytic bacteria are present in healthy humans and animals. Glycoproteins are major players in the mucus protective barrier in the gastrointestinal and other mucosal surfaces. In particular, the mucins, are responsible for the protective gel barrier. Mucus layers provide a physical barrier of protection from the microbiota in the large intestine, though there needs to be a functional interplay between this layer and mucin-degrading or mucin-utilizing bacteria in the intestinal microbiota for proper homeostasis [55]. Sialic acid produced by mucin decomposition is used as a carbon source for specific bacteria, and in the intestine, the sialic acid supplier and the user bacterium coexist in an exquisite balance [56]. It has also been suggested that the cross-feeding of degradation products "strategies through the expansion of carbohydrate acquisition abilities by gut bacteria" occurs between symbiotic bacteria [55-57].

On the other hand, if this symbiotic relationship is disrupted and the amount of free sialic acid in the intestine changes, the risk of infection by pathogenic bacteria increases [56]. In other words, the presence of a rich mucin layer is essential for maintaining diversity in the intestinal microbiota [55-57]. In this study, diet supplementation with limonoids + Spm or limonoids alone yielded an increase in the number of mucin-degrading bacteria. However, SD mice fed with limonoids + Spm survived longer than SD control mice, SD mice fed with limonoids or Spm alone. Especially, the life-extension rate (\%) of mice fed with Spm alone was less than $50 \%$ of that for mice fed with limonoid $+\mathrm{Spm}$. In view of the intestinal microbiota profiles of the groups, these results suggest that the effects of Spm and limonoids on survival rates and/or the intestinal microbiota in this model are different, which is why we pursued the composition of enterobacteria and their metabolites in greater detail.

SCFAs, one of the enterobacteria metabolites, are known to significantly affect host immunity [58]. The immune response induced by SCFAs and their receptors may be one of the primary strategies to maintain the health of the host (Figure 9). SCFAs are sensed by host cells through various G-protein coupled receptors (GPRs), such as GPR41, GPR43, and GPR109A, known as free fatty acid receptors, and the intracellular receptor [59]. GPR41 and GPR43, which suppress appetite and host insulin sensitivity [60], are SCFA receptors that have been recently identified in enteroendocrine cells [61-63] and correspond primarily to levels of acetic acid, propionic acid, and butyric acid. Acetic acid induces the activation of gastrointestinal inflammasomes through GPR43 and GPR109A [64,65], and it has also been reported that propionic acid causes proliferation of dendritic precursors in the bone marrow through GPR41, as well as acts to express molecules necessary for B cell differentiation to alter IgA production [66]. We showed that the addition of Spm to the diet clearly increased the proportion of Clostridiales and butyric acid in feces. 


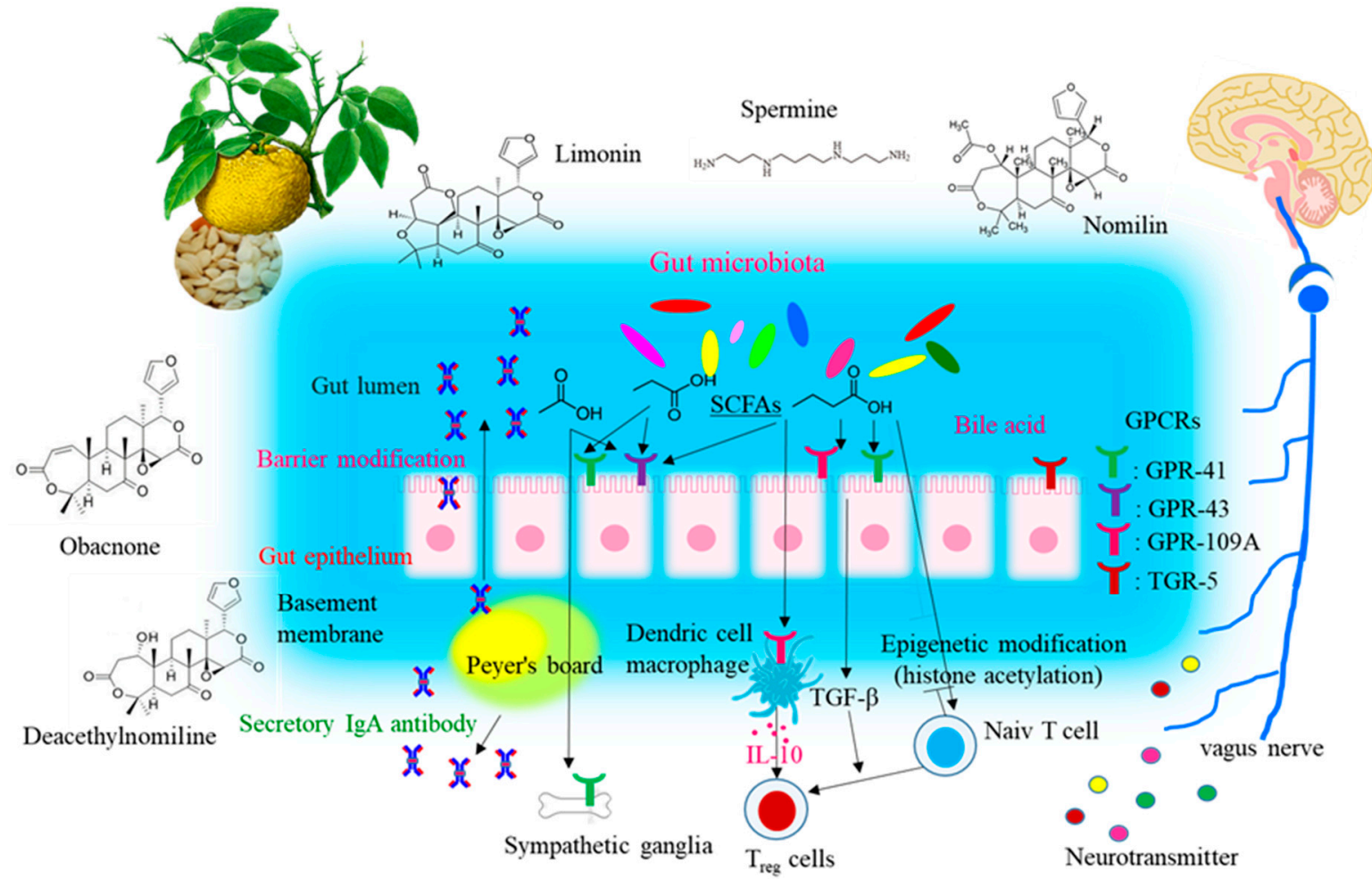

Figure 9. Conceptual diagram of immune responses of intestinal microbiota in the colon of SD and WT mice fed with limonoids + spermine or limonoids alone [56-66].

Butyric acid exhibits remarkable differentiation-inducing activity to regulatory $\mathrm{T}$ cells [22]. T cell induction, potentially through a mechanism that involves the production of SCFAs, acts through both immune and nonimmune cells to induce Foxp3 expression in CD4 T cells [21,22]. Foxp3 T cells comprise a large fraction of CD4 T cells in the small and large intestines and have critical functions in the maintenance of tolerance toward commensal microbiota and food antigens $[67,68]$. Although a fraction of intestinal $\mathrm{T}$ cells are derived from the thymus, many others are induced from SCFAs metabolized by commensal microbiota.

IgA helps colonization indigenous bacteria, although eliminated by infectious bacteria. We found that when SD and WT mice are fed with limonoids, the relative abundance ratio of mucolytic bacteria species such as Akkermansia, Bacteroides, and Bifidobacterium increased in these mice feses.

Some bacteria, like Bacteroides, have shown to have anti-inflammatory properties that are beneficial to the host. IgA secreted into the intestinal tract not only functions as an antibody responsible for eliminating pathogens and neutralizing toxins but also binds to Bacteroides through a polysaccharide and other bacterial species belonging to Firmicutes in the intestinal mucosa [69-71]. Bacteroides can coat themselves with IgA and become established in the intestinal mucus layer of the host. It is suggested that these interact and change the composition and metabolic function of the collective microbiota [69]. SCFAs absorbed from the large intestine and transferred to the blood also act on the immune cells of Peyer's patches in the small intestine, enhancing IgA production in the small intestine [70]. It is estimated that the small intestine produces several times the amount of IgA produced in the large intestine, but it is a prerequisite that a sufficient amount of SCFAs is produced by the metabolic activity of the intestinal microbiota [71,72]. In our investigation, it was suggested that SCFAs and IgA productions were significantly higher in mice fed with limonoids + Spm or limonoids alone than in SD and WT control mice. A positive correlation also was shown between the production levels of SCFAs and IgA. 
Recently, it was reported that some plasma cells (PC) in the CNS of mice with experimental autoimmune encephalomyelitis (EAE) originate in the gut and produce IgA. They showed that IgA + PC are dramatically reduced in the gut during EAE, and a reduction in IgA-bound fecal bacteria is seen in MS patients during disease relapse. Moreover, it was reported removal of plasmablast (PB) plus PC resulted in exacerbated EAE that was normalized by the introduction of gut-derived $\operatorname{Ig} \mathrm{A}+\mathrm{PC}$. They are suggested that $\operatorname{Ig} \mathrm{A}+\mathrm{PB}$ and/or PC mobilized from the gut may be playing in suppressing neuroinflammation [73].

Therefore, it suggests that when SD mice are fed with limonoids + Spm or limonoids, the mucus layer in the mouse Intestines was maintaining as a carbon and energy source to the intestinal microbiota [56]. As a result, it can be considered that the abundant SCFAs produced via the metabolism of the gut microbiome were abundantly absorbed by the host to more enhance the barrier function, enhancing IgA production. Recently, it was reported that some plasma cells (PC) in the CNS of mice with experimental autoimmune encephalomyelitis (EAE) originate in the gut and produce IgA. They showed that IgA + PC are dramatically reduced in the gut during EAE, and a reduction in IgA-bound fecal bacteria is seen in MS patients during disease relapse. Moreover, it was reported removal of plasmablast $(\mathrm{PB})$ plus $\mathrm{PC}$ resulted in exacerbated EAE that was normalized by the introduction of gut-derived IgA + PC. They are suggested that IgA + PB and/or PC mobilized from the gut may be playing in suppressing neuroinflammation [73].

Most importantly, it was observed at the same time by the combination diet of limonoids + Spm the maintenance of intestinal homeostasis and the suppression of inflammation in the brain of SD mice. Thus, our study that SCFAs and IgA production promoted by feeding limonoids + Spm in SD mice showed a correlation, suggests that the above immune response may be induced.

\section{Conclusions}

In this study, it has been observed neurodegeneration in the brains and dysbiosis of the intestine microbiome for SD control mice. Brain neurodegeneration and the diversity of intestinal microbiota involved in host intestinal homeostasis in SD mice were improved by ingesting the combination diet of limonoids and Spermine. These results suggest that yuzu seed limonoids and Spermine may help to maintain the homeostasis of intestinal microbiota and hypothalamic tissue in the sandhoff disease mouse model.

Author Contributions: Conceptualization, M.M.; methodology and validation, M.M., K.S. and G.K.; software, M.M. and G.K.; formal analysis, M.M., T.S., S.B., T.T., K.S. and G.K.; investigation, M.M., K.S. and G.K.; resources, M.M., K.S., A.Y., S.Y. and G.K.; data curation, M.M., K.S. and G.K.; writingoriginal draft preparation, M.M.; writing—review and editing, M.M.; visualization, M.M., K.S. and G.K.; supervision and project administration, M.M. and G.K.; funding acquisition, M.M., K.S., T.T. and G.K. All authors have read and agreed to the published version of the manuscript.

Funding: This research received no external funding.

Institutional Review Board Statement: The study was conducted according to the guidelines of the Declaration of Helsinki, and approved by the Animal Committee at Yokohama City University (approval number F-D-13-92).

Informed Consent Statement: Not applicable.

Data Availability Statement: The data presented in this study are available in manuscript.

Acknowledgments: The authors wish to thank Kyoto Mizuo and Fumihiro Matuo for providing the yuzu sample. We are grateful to Hirohisa Minamisawa (Nihon University, Japan) for his support; and to Shimadzu Co., Ltd. (Kyoto, Japan), Techno Suruga Laboratory Co., Ltd., and i-on Co., Ltd., for their help with the pathological experiments on mice, intestinal microbiota testing using next-generation sequencing, and short-chain fatty acid analyses.

Conflicts of Interest: The authors declare no conflict of interest. 


\section{References}

1. Minamisawa, M.; Suzuki, K.; Kawai, G.; Yamaguchi, A.; Yamanaka, S. Functional evaluation of yuzu (Citrus junos) extracts containing limonoids and polyamine for life extension. J. Funct. Foods 2017, 38, 591-600. [CrossRef]

2. Huang, J.-Q.; Trasler, J.M.; Igdoura, S.; Michaud, J.; Hanai, N.; Gravel, R.A. Apoptotic Cell Death in Mouse Models of GM2 Gangliosidosis and Observations on Human Tay-Sachs and Sandhoff Diseases. Hum. Mol. Genet. 1997, 6, 1879-1885. [CrossRef]

3. Yamato, O.; Hayashi, D.; Satoh, H.; Shoda, T.; Uchida, K.; Nakayama, H.; Sakai, H.; Masegi, T.; Murai, A.; Iida, T.; et al. Retrospective Diagnosis of Feline GM2 Gangliosidosis Variant 0 (Sandhoff-Like Disease) in Japan: Possible Spread of the Mutant Allele in the Japanese Domestic Cat Population. J. Vet. Med. Sci. 2008, 70, 813-818. [CrossRef]

4. Suzuki, K.; Yamaguchi, A.; Yamanaka, S.; Kanzaki, S.; Kawashima, M.; Togo, T.; Katsuse, O.; Koumitsu, N.; Aoki, N.; Iseki, E.; et al. Accumulated $\alpha$-synuclein affects the progression of GM2 gangliosidoses. Exp. Neurol. 2016, 284, 38-49. [CrossRef] [PubMed]

5. Ogawa, Y.; Sano, T.; Irisa, M.; Kodama, T.; Saito, T.; Furusawa, E.; Kaizu, K.; Yanagi, Y.; Tsukimura, T.; Togawa, T.; et al. FcR $\gamma$-dependent immune activation initiates astrogliosis during the asymptomatic phase of Sandhoff disease model mice. Sci. Rep. 2017, 7, 40518. [CrossRef] [PubMed]

6. Wada, R.; Tifft, C.J.; Proia, R.L. Microglial activation precedes acute neurodegeneration in Sandhoff disease and is suppressed by bone marrow transplantation. Proc. Natl. Acad. Sci. USA 2000, 97, 10954-10959. [CrossRef]

7. Jeyakumar, M.; Thomas, R.; Elliot-Smith, E.; Smith, D.A.; Van Der Spoel, A.C.; d'Azzo, A.; Hugh Perry, V.; Butters, T.D.; Dwek, R.A.; Platt, F.M. Central nervous system inflammation is a hallmark of pathogenesis in mouse models of GM1 and GM2 gangliosidosis. Brain 2003, 126, 974-987. [CrossRef]

8. Horiba, T.; Katsukawa, M.; Mita, M.; Sato, R. Dietary obacunone supplementation stimulates muscle hypertrophy, and suppresses hyperglycemia and obesity through the TGR5 and PPAR $\gamma$ pathway. Biochem. Biophys. Res. Commun. 2015, 463, 846-852. [CrossRef]

9. Ono, E.; Inoue, J.; Hashidume, T.; Shimizu, M.; Sato, R. Anti-obesity and anti-hyperglycemic effects of the dietary citrus limonoid nomilin in mice fed a high-fat diet. Biochem. Biophys. Res. Commun. 2011, 410, 677-681. [CrossRef] [PubMed]

10. Sato, R. Nomilin as an Anti-Obesity and Anti-Hyperglycemic Agent. Vitam. Horm. 2013, 91, 425-439. [CrossRef]

11. Matsumoto, M.; Kurihara, S.; Kibe, R.; Ashida, H.; Benno, Y. Longevity in Mice Is Promoted by Probiotic-Induced Suppression of Colonic Senescence Dependent on Upregulation of Gut Bacterial Polyamine Production. PLoS ONE 2011, 6, e23652. [CrossRef]

12. Desbonnet, L.; Clarke, G.R.; Shanahan, F.; Dinan, T.G.; Cryan, J.F. Microbiota is essential for social development in the mouse. Mol. Psychiatry 2014, 19, 146-148. [CrossRef]

13. De Palma, G.; Blennerhassett, P.; Lu, J.; Deng, Y.; Park, A.J.; Green, W.; Denou, E.; Silva, M.A.; Santacruz, A.; Sanz, Y.; et al. Microbiota and host determinants of behavioural phenotype in maternally separated mice. Nat. Commun. 2015, 6, 7735. [CrossRef] [PubMed]

14. Suganya, K.; Koo, B.-S. Gut-Brain Axis: Role of Gut Microbiota on Neurological Disorders and How Probiotics/Prebiotics Beneficially Modulate Microbial and Immune Pathways to Improve Brain Functions. Int. J. Mol. Sci. 2020, 21, 7551. [CrossRef] [PubMed]

15. Nobuyuki, S. Gut microbiota and brain function. J. Intest. Microbiol. 2017, 31, 23-32.

16. Andoh, A. Unexpected Functions of the Gut Microbiota as a Virtual Organ. Nihon Naika Gakkai Zasshi 2015, 104, 29-34. [CrossRef]

17. Bäckhed, F.; Manchester, J.K.; Semenkovich, C.F.; Gordon, J.I. Mechanisms underlying the resistance to diet-induced obesity in germ-free mice. Proc. Natl. Acad. Sci. USA 2007, 104, 979-984. [CrossRef]

18. Sekirov, I.; Russell, S.L.; Antunes, L.C.M.; Finlay, B.B. Gut Microbiota in Health and Disease. Physiol. Rev. 2010, 90, 859-904. [CrossRef]

19. Haghikia, A.; Li, X.S.; Liman, T.G.; Bledau, N.; Schmidt, D.; Zimmermann, F.; Landmesser, U. Gut microbiota-dependent Trimethylamine Noxide predicts risk of cardiovascular events in patients with stroke and is related to Proinflammatory monocytes. Arterioscler. Thromb. Vasc. Biol. 2018, 38, 2225-2235. [CrossRef]

20. Tan, Y.; Sheng, Z.; Zhou, P.; Liu, C.; Zhao, H.; Song, L.; Li, J.; Zhou, J.; Chen, Y.; Wang, L.; et al. Plasma Trimethylamine N-Oxide as a Novel Biomarker for Plaque Rupture in Patients With ST-Segment-Elevation Myocardial Infarction. Circ. Cardiovasc. Interv. 2019, 12, e007281. [CrossRef] [PubMed]

21. Atarashi, K.; Tanoue, T.; Ando, M.; Kamada, N.; Nagano, Y.; Narushima, S.; Suda, W.; Imaoka, A.; Setoyama, H.; Nagamori, T.; et al. Th17 Cell Induction by Adhesion of Microbes to Intestinal Epithelial Cells. Cell 2015, 163, 367-380. [CrossRef]

22. Furusawa, Y.; Obata, Y.; Fukuda, S.; Endo, T.A.; Nakato, G.; Takahashi, D.; Nakanishi, Y.; Uetake, C.; Kato, K.; Kato, T.; et al. Commensal microbe-derived butyrate induces the differentiation of colonic regulatory T cells. Nature 2013, 504, 446-450. [CrossRef] [PubMed]

23. Zhang, X.; Zhang, D.; Jia, H.; Feng, Q.; Wang, D.; Liang, D.; Wu, X.; Li, J.; Tang, L.; Li, Y.; et al. The oral and gut microbiomes are perturbed in rheumatoid arthritis and partly normalized after treatment. Nat. Med. 2015, 21, 895-905. [CrossRef] [PubMed]

24. Maeda, Y.; Kurakawa, T.; Umemoto, E.; Motooka, D.; Ito, Y.; Gotoh, K.; Hirota, K.; Matsushita, M.; Furuta, Y.; Narazaki, M.; et al. Dysbiosis Contributes to Arthritis Development via Activation of Autoreactive T Cells in the Intestine. Arthritis Rheumatol. 2016, 68, 2646-2661. [CrossRef] [PubMed]

25. Levy, M.; Thaiss, C.A.; Zeevi, D.; Dohnalová, L.; Zilberman-Schapira, G.; Mahdi, J.A.; David, E.; Savidor, A.; Korem, T.; Herzig, Y.; et al. Microbiota-Modulated Metabolites Shape the Intestinal Microenvironment by Regulating NLRP6 Inflammasome Signaling. Cell 2015, 163, 1428-1443. [CrossRef] 
26. Hoban, A.E.; Stilling, R.M.; Moloney, G.; Shanahan, F.; Dinan, T.G.; Clarke, G.; Cryan, J.F. The microbiome regulates amygdaladependent fear recall. Mol. Psychiatry 2018, 23, 1134-1144. [CrossRef]

27. Erny, D.; De Angelis, A.L.H.; Jaitin, D.; Wieghofer, P.; Staszewski, O.; David, E.; Keren-Shaul, H.; Mahlakoiv, T.; Jakobshagen, K.; Buch, T.; et al. Host microbiota constantly control maturation and function of microglia in the CNS. Nat. Neurosci. 2015, 18, 965-977. [CrossRef]

28. Soto, M.; Herzog, C.; Pacheco, J.A.; Fujisaka, S.; Bullock, K.; Clish, C.B.; Kahn, C.R. Gut microbiota modulate neurobehavior through changes in brain insulin sensitivity and metabolism. Mol. Psychiatry 2018, 23, 2287-2301. [CrossRef]

29. Descamps, H.C.; Herrmann, B.; Wiredu, D.; Thaiss, C.A. The path toward using microbial metabolites as therapies. EBioMedicine 2019, 44, 747-754. [CrossRef]

30. Kettle, H.; Louis, P.G.H.; Holtrop, G.; Duncan, S.H.; Flint, H.J. Modelling the emergent dynamics and major metabolites of the human colonic microbiota. Environ. Microbiol. 2015, 17, 1615-1630. [CrossRef]

31. Watanabe, K. Contribution of gut microbiota to the etiology of human diseases. Mod. Media. 2014, 60, 6-18.

32. Louis, P.; Flint, H.J. Diversity, metabolism and microbial ecology of butyrate-producing bacteria from the human large intestine. FEMS Microbiol. Lett. 2009, 294, 1-8. [CrossRef] [PubMed]

33. Louis, P.; Flint, H.J. Formation of propionate and butyrate by the human colonic microbiota. Environ. Microbiol. 2017, 19, 29-41. [CrossRef] [PubMed]

34. Zhang, Z.; Tang, H.; Chen, P.; Xie, H.; Tao, Y. Demystifying the manipulation of host immunity, metabolism, and extraintestinal tumors by the gut microbiome. Signal. Transduct. Target. Ther. 2019, 4, 1-34. [CrossRef]

35. Perry, R.J.; Peng, L.; Barry, N.A.; Cline, G.W.; Zhang, D.; Cardone, R.L.; Petersen, K.F.; Kibbey, R.G.; Goodman, A.L.; Shulman, G.I. Acetate mediates a microbiome-brain- $\beta$-cell axis to promote metabolic syndrome. Nature 2016, 534, 213-217. [CrossRef]

36. Sun, M.; Wu, W.; Chen, L.; Yang, W.; Huang, X.; Ma, C.; Chen, F.; Xiao, Y.; Zhao, Y.; Ma, C.; et al. Microbiota-derived short-chain fatty acids promote Th1 cell IL-10 production to maintain intestinal homeostasis. Nat. Commun. 2018, 9, 1-15. [CrossRef]

37. Wu, W.; Sun, M.; Chen, F. Microbiota metabolite short-chain fatty acid acetate promotes intestinal IgA response to mi-crobiota which is mediated by GPR. Mucosal. Immunol. 2017, 10, 946-956. [CrossRef] [PubMed]

38. Arpaia, N.; Campbell, C.; Fan, X.; Dikiy, S.; Van Der Veeken, J.; DeRoos, P.; Liu, H.; Cross, J.R.; Pfeffer, K.; Coffer, P.J.; et al. Metabolites produced by commensal bacteria promote peripheral regulatory T-cell generation. Nature 2013, 504, 451-455. [CrossRef]

39. Smith, P.M.; Howitt, M.R.; Panikov, N. The microbial metabolites, short-chain fatty acids, regulate colonic Treg cell ho-meostasis. Science 2013, 341, 569-573. [CrossRef]

40. Yoo, D.Y.; Kim, W.; Nam, S.M.; Kim, D.W.; Chung, J.Y.; Choi, S.Y.; Yoon, Y.S.; Won, M.-H.; Hwang, I.K. Synergistic Effects of Sodium Butyrate, a Histone Deacetylase Inhibitor, on Increase of Neurogenesis Induced by Pyridoxine and Increase of Neural Proliferation in the Mouse Dentate Gyrus. Neurochem. Res. 2011, 36, 1850-1857. [CrossRef]

41. Minamisawa, M.; Yoshida, S.; Uzawa, A. The functional evaluation of waste yuzu (Citrus junos) seeds. Food Funct. 2014, 5, 330-336. [CrossRef]

42. Kanda, Y. Investigation of the freely available easy-to-use software 'EZR' for medical statistics. Bone Marrow Transplant. 2013, 48, 452-458. [CrossRef]

43. Callahan, B.J.; Mcmurdie, P.J.; Rosen, M.J.; Han, A.W.; Johnson, A.J.A.; Holmes, S.P. DADA2: High-resolution sample inference from Illumina amplicon data. Nat. Methods 2016, 13, 581-583. [CrossRef]

44. Cox, L.M.; Sohn, J.; Tyrrell, K.L.; Citron, D.M.; Lawson, P.A.; Patel, N.B.; Iizumi, T.; Perez-Perez, G.I.; Goldstein, E.J.C.; Blaser, M.J. Description of two novel members of the family Erysipelotrichaceae: Ileibacterium valens gen. nov., sp. nov. and Dubosiella newyorkensis, gen. nov., sp. nov., from the murine intestine, and emendation to the description of Faecalibacterium rodentium. Int. J. Syst. Evol. Microbiol. 2017, 67, 1247-1254. [CrossRef]

45. Honda, K. Clostridia and the mucosal immune system. J. Intest. Microbiol. 2013, 27, 187-196.

46. Mihara, H.; Suzuki, N.; Muhammad, J.S.; Nanjo, S.; Ando, T.; Fujinami, H.; Kajiura, S.; Hosokawa, A.; Sugiyama, T. Transient receptor potential vanilloid 4 (TRPV4) silencing in Helicobacter pylori-infected human gastric epithelium. Helicobacter 2016, 22, 12361. [CrossRef] [PubMed]

47. Braak, H.; Del Tredici, K.; Bratzke, H.; Hamm-Clement, J.; Sandmann-Keil, D.; Rüb, U. Staging of the intracerebral inclusion body pathology associated with idiopathic Parkinson's disease (preclinical and clinical stages). J. Neurol. 2002, 249, 1. [CrossRef] [PubMed]

48. Hasegawa, S.; Goto, S.; Tsuji, H.; Okuno, T.; Asahara, T.; Nomoto, K.; Shibata, A.; Fujisawa, Y.; Minato, T.; Okamoto, A.; et al. Intestinal Dysbiosis and Lowered Serum Lipopolysaccharide-Binding Protein in Parkinson's Disease. PLoS ONE 2015, 10, e0142164. [CrossRef] [PubMed]

49. Hill-Burns, E.M.; Debelius, J.W.; Morton, J.T.; Wissemann, W.T.; Lewis, M.R.; Wallen, Z.D.; Peddada, S.D.; Factor, S.A.; Molho, E.; Zabetian, C.P.; et al. Parkinson's disease and Parkinson's disease medications have distinct signatures of the gut microbiome. Mov. Disord. 2017, 32, 739-749. [CrossRef]

50. Petrov, V.A.; Saltykova, I.V.; Zhukova, I.A.; Alifirova, V.M.; Zhukova, N.G.; Dorofeeva, Y.B.; Tyakht, A.V.; Kovarsky, B.A.; Alekseev, D.G.; Kostryukova, E.S.; et al. Analysis of Gut Microbiota in Patients with Parkinson's Disease. Bull. Exp. Biol. Med. 2017, 162, 734-737. [CrossRef] 
51. Kelly, L.P.; Carvey, P.M.; Keshavarzian, A.; Shannon, K.M.; Shaikh, M.; Bakay, R.A.E.; Kordower, J.H. Progression of intestinal permeability changes and alpha-synuclein expression in a mouse model of Parkinson's disease. Mov. Disord. 2014, 29, 999-1009. [CrossRef]

52. Forsyth, C.B.; Shannon, K.M.; Kordower, J.H.; Voigt, R.M.; Shaikh, M.; Jaglin, J.A.; Estes, J.D.; Dodiya, H.B.; Keshavarzian, A. Increased intestinal permeability correlates with sigmoid mucosa alpha-synuclein staining and endo-toxin exposure markers in early Parkinson's disease. PLoS ONE 2011, 6, e28032. [CrossRef]

53. Forslund, K.; Hildebrand, F.; Nielsen, T.R.; Falony, G.; Le Chatelier, E.; Sunagawa, S.; Prifti, E.; Vieira-Silva, S.; Gudmundsdottir, V.; Pedersen, H.K.; et al. Disentangling type 2 diabetes and metformin treatment signatures in the human gut microbiota. Nature 2015, 528, 262-266. [CrossRef]

54. Olson, C.A.; Vuong, H.E.; Yano, J.M.; Liang, Q.Y.; Nusbaum, D.J.; Hsiao, E.Y. The gut microbiota mediates the an-ti-seizure effects of the ketogenic diet. Cell 2018, 173, 1728-1741.e13. [CrossRef]

55. Okumura, R.; Kurakawa, T.; Nakano, T.; Kayama, H.; Kinoshita, M.; Motooka, D.; Gotoh, K.; Kimura, T.; Kamiyama, N.; Kusu, T.; et al. Lypd8 promotes the segregation of flagellated microbiota and colonic epithelia. Nat. Cell Biol. 2016, 532, 117-121. [CrossRef] [PubMed]

56. Jean-Félix, S.; Guillaume, L.B.; Philippe, V.; Mario, J.; Josée, H. Interactions of Intestinal Bacteria with Components of the Intestinal Mucus. Front. Cell Infect Microbiol. 2017, 7, 387. [CrossRef]

57. Turroni, F.; Milani, C.; Duranti, S.; Mancabelli, L.; Mangifesta, M.; Viappiani, A.; Lugli, G.A.; Ferrario, C.; Gioiosa, L.; Ferrarini, A.; et al. Deciphering bifidobacterial-mediated metabolic interactions and their impact on gut microbiota by a multi-omics approach. ISME J. 2016, 10, 1656-1668. [CrossRef] [PubMed]

58. Thomas, C.; Gioiello, A.; Noriega, L.; Strehle, A.; Oury, J.; Rizzo, G.; Macchiarulo, A.; Yamamoto, H.; Mataki, C.; Pruzanski, M.; et al. TGR5-Mediated Bile Acid Sensing Controls Glucose Homeostasis. Cell Metab. 2009, 10, 167-177. [CrossRef] [PubMed]

59. Dalile, B.; Van Oudenhove, L.; Vervliet, B.; Verbeke, K. The role of short-chain fatty acids in microbiota-gut-brain communication. Nature Reviews. Gastroenterol. Hepatol. 2019, 16, 461-478.

60. Sakamoto, M. The taxonomy of the genus Bacteroides and related taxa. J. Intest. Microbiol. 2016, 30, $119-127$.

61. Kimura, I.; Inoue, D.; Maeda, T.; Hara, T.; Ichimura, A.; Miyauchi, S.; Kobayashi, M.; Hirasawa, A.; Tsujimoto, G. Short-chain fatty acids and ketones directly regulate sympathetic nervous system via G protein-coupled receptor 41 (GPR41). Proc. Natl. Acad. Sci. USA 2011, 108, 8030-8035. [CrossRef] [PubMed]

62. Inoue, D.; Kimura, I.; Wakabayashi, M.; Tsumoto, H.; Ozawa, K.; Hara, T.; Takei, Y.; Hirasawa, A.; Ishihama, Y.; Tsujimoto, G. Short-chain fatty acid receptor GPR41-mediated activation of sympathetic neurons involves synapsin $2 \mathrm{~b}$ phosphorylation. FEBS Lett. 2012, 586, 1547-1554. [CrossRef] [PubMed]

63. McNelis, J.C.; Lee, Y.S.; Mayoral, R.; Van Der Kant, R.; Johnson, A.M.F.; Wollam, J.; Olefsky, J.M. GPR43 Potentiates $\beta$-Cell Function in Obesity. Diabetes 2015, 64, 3203-3217. [CrossRef]

64. Macia, L.; Tan, J.; Vieira, A.T.; Leach, K.; Stanley, D.; Luong, S.; Maruya, M.; McKenzie, C.I.; Hijikata, A.; Wong, C.; et al. Metabolite-sensing receptors GPR43 and GPR109A facilitate dietary fiber-induced gut homeostasis through regulation of the inflammasome. Nat. Commun. 2015, 6, 6734. [CrossRef] [PubMed]

65. Abbondio, M.; Palomba, A.; Tanca, A.; Fraumene, C.; Pagnozzi, D.; Serra, M.; Marongiu, F.; Laconi, E.; Uzzau, S. Fecal Metaproteomic Analysis Reveals Unique Changes of the Gut Microbiome Functions After Consumption of Sourdough Carasau Bread. Front. Microbiol. 2019, 10, 1733. [CrossRef] [PubMed]

66. Fukuda, S.; Toh, H.; Hase, K.; Oshima, K.; Nakanishi, Y.; Yoshimura, K.; Tobe, T.; Clarke, J.M.; Topping, D.L.; Suzuki, T.; et al. Bifidobacteria can protect from enteropathogenic infection through production of acetate. Nature 2011, 469, 543-547. [CrossRef]

67. Tsuji, M.; Komatsu, N.; Kawamoto, S.; Suzuki, K.; Kanagawa, O.; Honjo, T.; Hori, S.; Fagarasan, S. Preferential Generation of Follicular B Helper T Cells from Foxp3+ T Cells in Gut Peyer's Patches. Science 2009, 323, 1488-1492. [CrossRef] [PubMed]

68. Littman, D.R.; Rudensky, A.Y. Th17 and regulatory T cells in mediating and restraining inflammation. Cell 2010, 140, 845-858. [CrossRef] [PubMed]

69. Donaldson, G.P.; Ladinsky, M.S.; Yu, K.B.; Sanders, J.G.; Yoo, B.B.; Chou, W.-C.; Conner, M.E.; Earl, A.M.; Knight, R.; Bjorkman, P.J.; et al. Gut microbiota utilize immunoglobulin A for mucosal colonization. Science 2018, 360, 795-800. [CrossRef]

70. Chen, K.; Magri, G.; Grasset, E.K.; Cerutti, A. Rethinking mucosal antibody responses: IgM, IgG and IgD join IgA. Nat. Rev. Immunol. 2020, 20, 427-441. [CrossRef]

71. Yanagibashi, T.; Hosono, A.; Oyama, A.; Tsuda, M.; Suzuki, A.; Hachimura, S.; Takahashi, Y.; Momose, Y.; Itoh, K.; Hirayama, K.; et al. IgA production in the large intestine is modulated by a different mechanism than in the small intestine: Bacteroides acidifaciens promotes IgA production in the large intestine by inducing germinal center formation and increasing the number of IgA+ B cells. Immunobiology 2013, 218, 645-651. [CrossRef] [PubMed]

72. Nakajima, A.; Vogelzang, A.; Maruya, M.; Miyajima, M.; Murata, M.; Son, A.; Kuwahara, T.; Tsuruyama, T.; Yamada, S.; Matsuura, M.; et al. IgA regulates the composition and metabolic function of gut microbiota by promoting symbiosis between bacteria. J. Exp. Med. 2018, 215, 2019-2034. [CrossRef] [PubMed]

73. Rojas, O.L.; Pröbstel, A.K.; Porfilio, E.A.; Wang, A.A.; Charabati, M.; Sun, T.; Gommerman, J.L. Recirculating Intestinal IgAProducing Cells Regulate Neuroinflammation via IL-10. Cell 2019, 176, 610-624.e18. [CrossRef] [PubMed] 